\title{
Heat balance and eddies in the Peru-Chile current system
}

\author{
François Colas ${ }^{1,{ }^{*}}$, James C. McWilliams ${ }^{1},{\text { Xavier } \text { Capet }^{2} \text { and Jaison Kurian }}^{1}$ \\ ${ }^{1}$ Institute of Geophysics and Planetary Physics, University of California, Los Angeles, CA 90095-1567, USA \\ ${ }^{2}$ Laboratoire de Physique des Océans, Ifremer, Plouzané, France \\ *: Corresponding author : F. Colas, email address : francois@atmos.ucla.edu
}

\begin{abstract}
:
The Peru-Chile current System (PCS) is a region of persistent biases in global climate models. It has strong coastal upwelling, alongshore boundary currents, and mesoscale eddies. These oceanic phenomena provide essential heat transport to maintain a cool oceanic surface underneath the prevalent atmospheric stratus cloud deck, through a combination of mean circulation and eddy flux. We demonstrate these behaviors in a regional, quasi-equilibrium oceanic model that adequately resolves the mesoscale eddies with climatological forcing. The key result is that the atmospheric heating is large $\left(>50 \mathrm{~W} \mathrm{~m}^{-2}\right)$ over a substantial strip $>500 \mathrm{~km}$ wide off the coast of Peru, and the balancing lateral oceanic flux is much larger than provided by the offshore Ekman flux alone. The atmospheric heating is weaker and the coastally influenced strip is narrower off Chile, but again the Ekman flux is not sufficient for heat balance. The eddy contribution to the oceanic flux is substantial. Analysis of eddy properties shows strong surface temperature fronts and associated large vorticity, especially off Peru. Cyclonic eddies moderately dominate the surface layer, and anticyclonic eddies, originating from the nearshore poleward Peru-Chile Undercurrent (PCUC), dominate the subsurface, especially off Chile. The sensitivity of the PCS heat balance to equatorial intra-seasonal oscillations is found to be small. We demonstrate that forcing the regional model with a representative, coarseresolution global reanalysis wind product has dramatic and deleterious consequences for the oceanic circulation and climate heat balance, the eddy heat flux in particular.
\end{abstract}

Keywords: Regional modelling-South-East Pacific-Heat Balance-Oceanic eddies-Regional climate 


\section{Introduction}

The coastal margin and adjacent ocean of western South America is climatically unique. It is home to El Niño near the equator. Further south off Peru and Chile it has the distinctive elements of a stratus cloud deck; alongshore-parallel winds; upwelling boundary currents and mesoscale eddies; sharp changes in the surface heat-moisture-drag fluxes near the coastline; high biological productivity; marine and anthropogenic aerosol precursors emissions; and subsurface hypoxia/anoxia. Some of these features have rather small lateral scales, which can make them difficult to simulate. This region often has relatively high errors in global climate models with, e.g., warm bias in sea surface temperature (Collins et al. 2006), too little stratus cloud cover, and too much solar radiation at the surface (Cronin et al. 2006), and hence too much evaporation in compensation and too little cooling by oceanic currents (de Szoeke et al. 2010). Furthermore, there is significant upscaling potential for regional influences on global patterns. By regional intervention in the sea surface temperature (SST) in a global coupled model, Large and Danabasoglu (2006) show significant, favorable impact on tropical precipitation around the globe. Using global coupled models, Manganello and Huang (2009) show that reducing the warm SST bias over the region (by applying an empirical heat flux correction) has an important influence on the ENSO variability, and Yu and Mechoso (1999) show that imposed stratus variations off Peru influence the mean and inter-annual variability of SST broadly in the eastern equatorial Pacific. In this context part of the growing interest for this region led to the development of the VOCALS experiment (CLIVAR VAMOS Ocean-Cloud-Atmosphere-Land Study; Wood et al. 2007; Mechoso and Wood 2010) to better understand the regional climate dynamics and its global importance.

A particularly important issue is the upper-ocean heat balance in the PeruChile Current System (PCS). A relatively cold oceanic surface is necessary to maintain the stratus cloud deck. Climatology analyses (Yu and Weller 2007; Large and Yeager 2009) and recent observations show a strong atmospheric heating of the ocean by $40-80 \mathrm{~W} \mathrm{~m}^{-2}$ (Colbo and Weller 2007; de Szoeke et al. 2010) in an offshore coastal-transition zone extending over many hundred $\mathrm{km}$; this heating is greater off Peru than Chile, and greater toward the coast. Consequently, the equilibrium oceanic circulation must provide a balancing cooling flux to keep the surface from warming and to maintain the SST conditions necessary for the stratus clouds. In equilibrium the vertical oceanic heat flux is not sufficient, and a vertically integrated lateral flux is necessary. Colbo and Weller (2007) conclude that the cooling by offshore Ekman transport, due to the equatorward wind stress, is too small to provide this heat balance. Hence, the remaining oceanic advective heat flux must occur through a combination of mean circulation and mesoscale eddy transport that laterally redistribute the cold water brought into the upper ocean by the coastal upwelling. de Szoeke et al. (2010) and Zheng et al. (2011) show that climate models generally have a biased heat balance in the PCS and suggest that it is a consequence of their incapacity to accurately resolve the nearshore upwelling and the eddy transport. The wind is the primary forcing for the upwelling, and its nearshore structure is also not well modeled with coarse atmospheric model resolution.

In the PCS, as in other eastern boundary regions, the mean flow is weaker than its mesoscale eddy velocities, and the eddy fluxes are important contributors 
to momentum and tracer balances (Marchesiello et al. 2003; Capet et al. 2008a). As yet few modeling studies have covered the entire PCS with a horizontal resolution high enough to resolve the mesoscale (i.e., $d x<10 \mathrm{~km}$ ). In this paper we report on the upwelling and eddy structures and on regional heat balance in a high-resolution quasi-equilibrium solution of the PCS circulation. The methodology and results are extensions of previous PCS simulations by Penven et al. (2005) and Colas et al. (2008) and are described in Sec. 2. Xi et al. (2007) and Toniazzo et al. (2010) are recent coupled-model simulation studies of the PCS with marginal eddy resolution (i.e., $0.5^{\circ}$ in a large-regional domain and $0.33^{\circ}$ in a global domain, respectively). Zheng et al. (2010) is an oceanic simulation study with high resolution (i.e., $\leq 1 / 12^{\circ}$ in a nearly global domain). Some results of these very recent studies are described and discussed in Sec. 4.

The general characteristics and empirical assessment of the simulation are in Sec. 3, with particular attention to the nearshore upwelling, mean hydrographic structure, alongshore currents, and mesoscale activity. The regional heat balance is in Sec. 4, showing how both mean advection and mesoscale eddy transport do provide offshore cooling over a large offshore region under strong air-sea warming. Further analysis of mesoscale eddy properties is in Sec. 5, including an eddy census showing a large population of subsurface anticyclonic vortices originating from the nearshore poleward Peru-Chile Undercurrent (PCUC). The sensitivities of the regional circulation and heat balance to intra-seasonal equatorial fluctuations at the domain boundary and to the wind forcing by a typical global reanalysis product are tested in Secs. 6 and 7. The former does not cause a strong climate change in the PCS, while the latter has dramatic, deleterious consequences for the oceanic response. Conclusions are in Sec. 8.

\section{Model Configuration}

To simulate the regional circulation including the mean currents, seasonal cycle, and mesoscale intrinsic variability, we configure the Regional Oceanic Modeling System (ROMS "UCLA"; Shchepetkin and McWilliams 2005, 2009) to simulate a realistic quasi-equilibrium solution of the South American West Coast region in the Southeast Pacific. ROMS is a free-surface, split-explicit model solving the hydrostatic primitive equations using terrain-following curvilinear vertical coordinates. It has been successfully used in previous studies of quasi-equilibrium dynamics of eastern boundary upwelling systems (Marchesiello et al. 2003; Penven et al. 2005; Marchesiello and Estrade 2007; Capet et al. 2008a; Veitch et al. 2010; Mason et al. 2011).

The configuration covers a domain from $15^{\circ} \mathrm{N}$ to $41^{\circ} \mathrm{S}$ and from $100^{\circ} \mathrm{W}$ to the South American coast (Fig. 1) with open-boundary conditions at its western and southern edges (Colas et al. 2008). The horizontal resolution $(7.5 \mathrm{~km})$ is high enough to resolve the nearshore upwelling dynamics and mesoscale eddies because the baroclinic Rossby deformation radius is around $150 \mathrm{~km}$ in the northern part of the domain and diminishes to $25 \mathrm{~km}$ in the south. We use 32 vertical levels, and the model bathymetry has a minimum depth of $20 \mathrm{~m}$. The bottom topography is interpolated from the SRTM30 database (Becker et al. 2009). The open-boundary conditions used here are described in Mason et al. (2010), and they allow for both incoming information from the boundary data and free evolution in the simulated 
flow. Subgrid-scale vertical mixing is parameterized using the KPP boundary layer formulation (Large et al. 1994), and the dominant lateral mixing is due to the upstream-biased advection operator.

The surface forcing is mean-monthly climatology. Heat and freshwater fluxes are from COADS (Da Silva et al. 1994), and wind stress is computed from QSCAT scatterometer data (SCOW monthly climatology with a resolution of $0.25^{\circ}$; Risien and Chelton 2008). Open-boundary information is a monthly climatology taken from SODA (Carton and Giese 2008) over the period 2000-2006. To augment the surface heat flux climatology, we add a weak restoring tendency (Barnier et al. 1995) using a 9-km Pathfinder SST climatology (Casey and Cornillon 1999). It provides an effective restoring time for the boundary layer of about 60 days, which therefore causes little damping of faster phenomena like mesoscale eddies (except for the SST signature of long-lived eddies). It does have the effect of boosting the model's air-sea heating over the original COADS estimate, but the result is within the range of other estimates (Sec. 1). The same type of restoring is also used for surface salinity with respect to the COADS sea surface salinity. Pre-processing tools are adapted from the package developed by Penven et al. (2008). The model is initialized with mean January temperature and salinity from SODA and zero velocity. An integration is made for 13 years; the first three years are considered the spin-up and discarded from the equilibrium analysis. We denote this quasiequilibrium solution as SA-QCOW.

\section{Regional Circulation and Variability}

In this section we examine some general characteristics of the mean circulation in the PCS, coastal upwelling, seasonal cycle, and eddy activity. In several respects the present study is an extension of the Peruvian quasi-equilibrium simulation in Penven et al. (2005), so some of its topics are not repeated.

Upwelling is ubiquitous along the South American West Coast (Fig. 1) as indicated by the continuous strip of cold water nearshore. Signatures of upwelled cold water extend offshore through the distortion of the upwelling front by numerous filaments, squirts, and eddies along the coasts of Peru and Chile (northern and southern subdomain in Fig. 1, respectively). Alongshore equatorward wind is the primary forcing of coastal upwelling along an eastern boundary, and the PCS winds are upwelling-favorable all year, with two extrema around $15^{\circ} \mathrm{S}$ and $30^{\circ} \mathrm{S}$ (Fig. 2). The wind has a weakening transition toward the coast (partly resolved in QSCAT except for the nearshore part within $50 \mathrm{~km}$ ), giving rise to a cyclonic wind-stress curl that induces further upwelling by Ekman suction.

The geographically distinct wind extrema and the dynamical effects of increasing Coriolis frequency $f$ with latitude combine to make the Peru and Chile circulations somewhat different, and we separate them in many of the following analyses; in particular, we will make separate alongshore averages for the Peru region (7$\left.13^{\circ} \mathrm{S}\right)$ and Chile region $\left(22-28^{\circ} \mathrm{S}\right)$, utilizing the average orientation of the coastline in these sectors to define alongshore and cross-shore directions; the VOCALS region around $20^{\circ} \mathrm{S}$ lies in between them, both geographically and in its circulation behavior. The seasonal cycle in the alongshore wind $\tau^{y}$ has a winter maximum and a summer minimum off Peru; an overall weaker amplitude off northern Chile; and a winter minimum and summer maximum in central Chile (Fig. 2). In Peru 
the upwelling is at its maximum in winter when the near-surface stratification is weak, and the maximum upwelling season does not have the strongest upwelling front (Strub et al. 1998); this is different from other mid-latitude eastern-boundary upwelling systems (the northern Benguela being another exception; Veitch et al. 2010), for example off central Chile, where maximum upwelling occurs in the summer when the near-surface stratification is largest. The Peru System has an enhanced Ekman transport $\propto \tau^{y} / f$ compared to the Chile System because it is nearer the equator with smaller $f$, and the coastal upwelling strip is narrower off northern Chile in part because the Rossby deformation radius (also $\propto 1 / f$ ) is smaller, which influences the wind response and mesoscale eddy patterns (Fig.1).

\subsection{Hydrographic Structure}

In situ hydrographic measurements are relatively sparse in the Southeast Pacific. The simulated mean hydrographic structure is assessed against the CARS climatology ${ }^{1}$. Overall, there is good agreement between the model solution and the temperature observations (Fig. 3). The model thermocline is somewhat too diffuse both off Peru and Chile; there is little bias near the surface, but the difference is $0.5-1^{\circ} \mathrm{C}$ at a $100 \mathrm{~m}$ depth. The mean thermocline off Peru is quite sharp and shallow, while it is deeper and broader off Chile. In this paper we focus on temperature because it is relevant to heat balance and it dominates over salinity in the buoyancy force and pycnocline baroclinic pressure gradients by typically a factor of three or more. Toniazzo et al (2010) stress the importance of salinity in setting a non zero mean advection tendency for density. This issue is not the focus of our paper.

Nearshore upwelling is evident in the isotherm tilt that is similar between the model and CARS. The annual-mean temperature of upwelled water on the continental shelf is $16^{\circ} \mathrm{C}$ and $15^{\circ} \mathrm{C}$ off Peru and Chile, respectively; the latter is similar to observations off Chile (Letelier et al. 2009). There are hints of a possible cold bias of the very nearshore model SSTs. Comparison with Pathfinder data (not shown) indicates that, indeed, the model SSTs are colder very nearshore at many locations with an annual mean bias $\gtrsim 1^{\circ} \mathrm{C}$, in spite of the SST restoring (Sec. 2). This discrepancy may be partly explained by sampling bias in the nearshore region from cloud contamination. It may also be due to the inaccurate determination of the wind-weakening transition at the coast (Capet et al. 2004): if nearshore wind forcing is overestimated, coastal upwelling possibly is overestimated giving an overly cold temperature at the coast. Such a bias is reported in previous studies of upwelling regions (Penven et al. 2005; Veitch et al. 2010; Mason et al. 2011).

Another bias (not shown) is model underestimation of the shallow subsurface salinity minimum observed in the region (Karstensen 2004). At $28^{\circ} \mathrm{S}, 100 \mathrm{~m}$ depth, and $300 \mathrm{~km}$ offshore, CARS salinity is $\lesssim 34.3$ PSU, whereas the modeled salinity is $\lesssim 34.4$ PSU. This difference cannot be explained only by the information in the open-boundary conditions: in SODA the salinity minimum bias is only about half as large as in our simulation. Other potential causes for this bias are advection errors that induce spurious diapycnal mixing (Marchesiello et al. 2009) and errors in the freshwater forcing (Karstensen 2004).

\footnotetext{
1 http://www.marine.csiro.au/ dunn/cars2006/
} 
We compare the mixed-layer depth $(m l d)$ in the solution with the observational climatology by de Boyer-Montegut et al. (2004). In their criterion mld is the depth of a $0.2^{\circ} \mathrm{C}$ temperature difference relative to the temperature at $10 \mathrm{~m}$ depth. There is a good general agreement (Fig.3) between the solution and the observations at the regional scale, showing similar mld deepening offshore. The model mld is slightly deeper, especially in the nearshore (upwelling) region, but the observations there have to be regarded with caution because of their coarse horizontal resolution $\left(2^{\circ}\right)$. The seasonal nearshore variation in the model solution ranges from $15-20 \mathrm{~m}$ in summer (January-March) to $40-50 \mathrm{~m}$ in winter (July-September). The mld is deeper off Chile than off Peru. Mixed-layer structure and seasonality are important elements of the near-surface heat balance in the PCS (Sec. 4).

\subsection{Upwelling and Nearshore Currents}

Alongshore averages of alongshore and cross-shore velocities in the PCS have typical structures for eastern boundary upwelling systems (Fig. 4; Capet et al. 2008a). The dominant equatorward wind stress and associated cyclonic curl cause an equatorward near-surface current and a poleward undercurrent (the PCUC) along the continental slope (Strub et al. 1998). The equatorward surface current is particularly intense nearshore in the coastal upwelling region, the Peru Coastal Current (ibid). The cross-shore circulation consists of an offshore flow in the Ekman layer and a weaker onshore flow in the underlying thermocline. Vertical velocity $w$ is positive over the shelf, indicating the coastal upwelling, and strongest near the coast. Coastal upwelling and horizontal circulation are more superficial and broader for Peru than for Chile. This is due to the difference in shelf topography ${ }^{2}$ and due to the poleward decrease of the Rossby radius through the decrease of density stratification and increase in $|f|$. Also, the coastally influenced zone tends to broaden due to the equatorward increase in propagation speed of Rossby waves that cause the coastal signals to be propagated offshore (Philander and Yoon 1982; Colas et al. 2008). The nearshore currents off Peru and Chile have strong horizontal and vertical shears, hence generate mesoscale eddy activity due to both barotropic and baroclinic instabilities (Sec. 3.3).

The few observations of the surface coastal currents show rough consistency with the model in both speed $\left(>10 \mathrm{~cm} \mathrm{~s}^{-1}\right)$ and structure off Peru and Chile. The PCUC has its core centered at a depth of approximately $150 \mathrm{~m}$ over the Peruvian slope, with a maximum speed $\lesssim 10 \mathrm{~cm} \mathrm{~s}^{-1}$, similar to observations by Brink et al. (1983) and Huyer et al. (1991). A second maximum of poleward flow occurs offshore at approximately $100 \mathrm{~m}$ depth. It is recognizable as the Peru-Chile Countercurrent (Strub et al. 1998) and is comparable to observations by Huyer et al. (1991) and consistent with the simulation by Penven et al. (2005), which show that this offshore poleward flow is related to the cyclonic wind-stress curl through Sverdrup balance. Off Chile the PCUC core is deeper than off Peru, at about 250 $\mathrm{m}$ depth with a maximum speed of about $13 \mathrm{~cm} \mathrm{~s}^{-1}$, consistent with observations (Shaffer et al. 1999; Blanco et al. 2001). Its cross-shore extent is confined within about $50 \mathrm{~km}$ from the slope. A surface outcropping of this poleward flow occurs

2 Off Peru the shelf is about $100 \mathrm{~km}$ wide, while it is much narrower off Chile. Estrade et al. (2008) show that both the location of the upwelling and its width vary with the topography. 
at 50-100 km offshore, right outside the surface equatorward current. The vertical extent of the PCUC is different in the two regions: it reaches no deeper than $300 \mathrm{~m}$ off Peru, whereas it goes deeper than $500 \mathrm{~m}$ off Chile. The poleward deepening of the PCUC vertical extent is noted by Penven et al. (2005) for Peru and by Veitch et al. (2010) for the Benguela System; both papers suggest this deepening could be explained by barotropic potential vorticity conservation, i.e., $f / H$ is conserved with increasing $H$ and $f$.

\subsection{Eddy Kinetic Energy}

The surface eddy kinetic energy (EKE) is a bulk measure of mesoscale activity. In eastern boundary regions, mesoscale eddies are mainly generated by instabilities of the alongshore currents, both in the nearshore upwelling region (through baroclinic and barotropic energy conversions) and in the region further offshore (mainly through baroclinic conversion; Marchesiello et al. 2003; Capet et al. 2008a). We calculate surface geostrophic EKE with velocities derived from sea surface height gradients for both the model solution and altimetry (we use here the DUACS updated global MSLA merged product for the period 2001-2006; Pascual et al. 2006). Velocity fluctuations are computed relative to the seasonal mean geostrophic velocity with a temporal high-pass filter to extract intra-seasonal and mesoscale intrinsic variability. The simulation data are spatially smoothed and temporally averaged (as described in Capet et al. 2008a) to be more consistent with altimetry sampling characteristics.

The model-data comparison for the spatial distribution of annual-mean EKE is in Fig. 5. Taking a coarse-grained perspective in light of the sampling uncertainty for eddy statistics (Sec. 4), we see fairly good agreement. There are two distinct alongshore regions of large EKE $>60 \mathrm{~cm}^{2} \mathrm{~s}^{-2}$ : off Peru $\left(6-18^{\circ} \mathrm{S}\right)$ and off Chile $\left(24-36^{\circ} \mathrm{S}\right)$. Local maxima $>100 \mathrm{~cm}^{2} \mathrm{~s}^{-2}$ are observed around $10^{\circ} \mathrm{S}, 17.5^{\circ} \mathrm{S}$, $27.5^{\circ} \mathrm{S}$, and $34^{\circ} \mathrm{S}$. These maxima are reproduced in the simulation, although they are underestimated at $34^{\circ} \mathrm{S}, 17-18^{\circ} \mathrm{S}$ (near the Pisco - San Juan upwelling plume, as previously discussed in Penven et al. 2005) and off Peru north of $10^{\circ} \mathrm{S}$. The underestimations may be partly due to the absence in the SODA boundary conditions of intra-seasonal equatorial signals that propagate poleward as coastal waves (Sec. 6), and they may be partly due to the incomplete model resolution of the full range of mesoscale variability. Nearshore wind effects are missing in QSCAT which may modify energetic eddy activity anchored by orographic irregularities (Castelao and Barth 2006). As in other major upwelling systems, there is an EKE nearshore minimum in both the simulation and in the observations. This supports the idea that EKE originates from instabilities in the nearshore region that amplify while moving offshore (e.g., Marchesiello et al. 2003). Seasonal variation of the EKE intensity (not shown) is rather weak, around $10 \%$. The offshore regions of Peru and Chile show an EKE maximum in fall and a minimum in spring. The EKE comparison with satellite altimetry measurements indicates that the simulation credibly represents the upper-ocean mesoscale eddies over the region. 


\section{Upper Ocean Heat Balance}

As discussed in Sec. 1, measurements and analyses show a mean net warming heat flux from the atmosphere to the ocean of $40-80 \mathrm{~W} \mathrm{~m}^{-2}$ over a wide crossshore swath in the Southeast Pacific, and this warming has to be compensated by cooling through oceanic lateral transport. At an offshore buoy site $\left(20^{\circ} \mathrm{S}, 85^{\circ} \mathrm{W}\right)$, Colbo and Weller (2007) estimate that the oceanic eddy flux divergence has an important contribution to the heat balance, comparable to the cooling by largescale advection that includes Ekman transport, which by itself is insufficient for equilibrium balance.

The time-mean oceanic heat balance integrated over the upper ocean is

$$
\begin{aligned}
\int_{z_{0}}^{\eta} \rho_{0} C_{p} \partial_{t} \bar{T} d z & =-\int_{z_{0}}^{\eta} \rho_{0} C_{p} \nabla \cdot \overline{\mathbf{u} T} d z+Q_{a t m}-\left.\rho_{0} C_{p} \overline{\kappa_{v} \partial_{z} T}\right|_{z_{0}} \\
\mathcal{T} & =\quad \mathcal{A}+Q_{a t m}+\mathcal{D}
\end{aligned}
$$

where $\rho_{0}$ is mean density, $C_{p}$ is heat capacity, $\mathbf{u}$ is $3 \mathrm{D}$ velocity, $T$ is temperature, $\kappa_{v}$ is subgrid-scale vertical eddy diffusivity, and $Q_{a t m}$ is the net ocean-atmosphere heat flux (including surface fluxes and penetrating shortwave radiation). $\eta$ is the sea surface elevation, and $z_{0}$ is the base of the upper-ocean layer. The quantities in the second line of (1) are defined in relation to those just above. The advection $\mathcal{A}$ is decomposed into eddy $\mathcal{A}_{\text {eddy }}$ and mean circulation $\mathcal{A}_{\text {mean }}$ contributions:

$$
\begin{aligned}
\mathcal{A}_{\text {eddy }} & =-\int_{z_{0}}^{\eta} \nabla \cdot \overline{\mathbf{u}^{\prime} T^{\prime}}=\mathcal{A}-\mathcal{A}_{\text {mean }} \\
\mathcal{A}_{\text {mean }} & =-\int_{z_{0}}^{\eta} \nabla \cdot \overline{\mathbf{u}} \bar{T},
\end{aligned}
$$

where overbar ${ }^{-}$is the time average over 10 years of the solution, and prime ${ }^{\prime}$ is the fluctuation. A contribution to $A_{\text {mean }}$ by the Ekman transport is estimated from $\mathbf{u}_{\mathbf{e k}} \cdot \nabla S S T$, with $\mathbf{u}_{e k}=(\hat{\mathbf{z}} \times \tau) /\left(\rho_{0} f h_{b l}\right)$ and $h_{b l}$ the boundary layer depth determined by the KPP parameterization. The heat-storage trend $\mathcal{T}$ is negligible when averaged over a long-enough period. Also, by integrating over a deep enough layer (here $z_{0}=200 \mathrm{~m}$, i.e., significantly deeper than the maximum boundarylayer depth), $\mathcal{D}$ becomes negligible $\left(|\mathcal{D}| \lesssim 1 \mathrm{~W} \mathrm{~m}^{-2}\right.$; not shown). Then (2) is mainly a balance between $\mathcal{A}<0$ and $Q_{a t m}>0$.

Maps of $\mathcal{A}_{\text {eddy }}$ and $\mathcal{A}_{\text {mean }}$ in our simulations show considerable spatial variability offshore that largely cancels in their multi-year sum, $-Q_{a t m}$, which is much smoother (Capet et al. 2008a). This variability tends to smooth out slowly when averaged over a much longer period (many tens of years). This means that singlepoint heat balances are hard to estimate, as noted by Colbo and Weller (2007) and Toniazzo et al (2010). This is not a surprise from the perspective of statistical estimation theory applied to eddy measurements (Flierl and McWilliams 1979): heat flux covariances are typically a small fraction of the product of velocity and temperature anomaly amplitudes and the sampling error decreases as the inverse square root of the measurement time. (EKE and other variance estimates also converge slowly, but they are generally more reliable than fractional covariance estimates.) Nevertheless, there is a degree of spatial organization in $\mathcal{A}$ that is robust with respect to the averaging period (see Fig. 7 below), especially within a 
few hundred $\mathrm{km}$ from the shore. The alongshore averaged patterns, which is what we show here, are significantly more robust ${ }^{3}$ than horizontal maps (e.g., Capet et al. 2008, Zheng et al. 2010).

Alongshore-averaged cross-sections of $\mathcal{A}_{\text {eddy }}$ and $\mathcal{A}_{\text {mean }}$ are in Fig. 6 for Peru $\left(7-15^{\circ} \mathrm{S}\right)^{4}$ and Chile $\left(25-35^{\circ} \mathrm{S}\right)$. The main balance between $Q_{a t m}$ and $\mathcal{A}$ is obvious (Fig. 6a,b). $Q_{a t m}$ values are in approximate agreement with the observations in the region (Sec. 1). The mean advection provides significant cooling nearshore (Fig. 6c,d). It is largest near the coast, i.e., $150 \mathrm{~W} \mathrm{~m}^{-2}$ within $150 \mathrm{~km}$ of the shore off Peru and larger than $50 \mathrm{~W} \mathrm{~m}^{-2}$ off Chile, in association with upwelling and equatorward cold advection by the alongshore current (Fig.4). The compensating nearshore eddy advection is significantly warming (greater than $50 \mathrm{~W} \mathrm{~m}^{-2}$ and about $20 \mathrm{~W} \mathrm{~m}^{-2}$, respectively, for Peru and Chile). Offshore in the Chile region, there is a narrow band (about $100 \mathrm{~km}$ ) of distinct cooling supplied by eddy advection $\left(30-40 \mathrm{~W} \mathrm{~m}^{-2}\right)$ where the mean advection contribution almost vanishes (Fig. 6d). Further offshore, the eddy contribution is negligible, leaving the mean advection balancing the net atmospheric flux $\left(20-30 \mathrm{~W} \mathrm{~m}^{-2}\right)$. Off Peru the situation is rather different with a broad offshore region $(300-600 \mathrm{~km}$ from the coast) of significant eddy cooling $\left(20-30 \mathrm{~W} \mathrm{~m}^{-2}\right)$, almost as large as the mean advection (Fig. 6c). In both regions cooling by Ekman transport is only a fraction of the total advection offshore (Fig. 6a,b). It is substantial in a nearshore strip that extends further offshore off Peru $(\sim 150 \mathrm{~km})$ than off Chile (see Sec.3). To assess the sampling accuracy, we compute separate averages for years 1-6 and 7-12 (Fig. 7). Both the eddy and mean advection profiles are similar (Fig. 7a,b), implying that the sampling accuracy is sufficient for these alongshore, multi-year averages.

Next, we examine the depth structure of heat advection (Fig. 8). In the nearshore for both Peru and Chile, $\mathcal{A}$ exhibits a deep cooling related to the upwelling and to the alongshore advection over the shelf (Fig. 8c,d). The nearshore eddy advection shows a warming that extends comparably deep (Fig. 8a,b). Offshore there is cooling associated with mean Ekman transport and geostrophic advection, and eddy advection shows warming over the upper part of the mixed layer and cooling below. After integrating to $z_{0}=-200 \mathrm{~m}$, the offshore eddy contribution is a net cooling, which is almost entirely a consequence of lateral flux.

To further interpret the eddy advection, we examine the eddy buoyancy flux components in Fig. 9, with $b=-g \rho / \rho_{0}$ mostly dominated by heat, but with some contribution from salinity in the offshore surface layer and PCUC core. The cross-shore lateral flux, $\overline{u^{\prime} b^{\prime}}$, is essentially shoreward and is largest in the upper pycnocline, where it acts to flatten the upwelling-tilted mean isothermal surfaces (Fig. 9a,b). This flux persists far offshore in the pycnocline, but it weakens in the surface layer, consistent with rather weak offshore eddy SST anomalies. $\overline{u^{\prime} b^{\prime}}$ is stronger and shallower off Peru than Chile, corresponding to the thermocline structures for the two regions (Fig. 3). The alongshore flux $\overline{v^{\prime} b^{\prime}}$ is not shown here because it provides a negligible contribution to the flux divergence; i.e., $\partial_{y} \overline{v^{\prime} b^{\prime}} \ll \partial_{x} \overline{u^{\prime} b^{\prime}}$. The vertical flux is upward, $\overline{w^{\prime} b^{\prime}}>0$ (Fig. 9c,d), and it peaks within the surface

3 Alongshore averaging over 7 (Peru) to 10 (Chile) degrees increases the number of independant realizations by a factor of at least 3 (off Peru where the deformation radius, and hence the eddy correlation length, is largest). Off Chile the factor may be closer to 10 .

4 The transition region between Peru and Chile $\left(17-22^{\circ} \mathrm{S}\right)$ is where most VOCALS measurements were made. It has a heat balance somewhat similar to Peru. 
boundary layer (except in the lower PCUC off Chile; Fig. 9d). Its vertical divergence provides the pattern of warming-above/cooling-below, which is an eddy restratification tendency in the upper ocean largely in opposition to vertical mixing by boundary-layer turbulence and perhaps by other small-scale processes like near-inertial shear instability. Lateral flux and vertical restratification are typical of eddy generation by baroclinic instability, as well as near-surface frontal and filamentary processes (Capet et al. 2008b; McWilliams et al., 2009). Both fluxes contribute to conversion of mean available potential energy into eddy energy. The lateral eddy cooling occurs primarily in the upper pycnocline. It then acts to cool the SST when it is connected to the surface by small-scale vertical turbulent mixing that is stronger than the eddy restratification effect; e.g., it occurs above the deepest mixed layer in winter, typically $60-80 \mathrm{~m}$ for Peru and $100 \mathrm{~m}$ or more for Chile.

In other simulations with much higher horizontal resolution $(\delta x \lesssim 1 \mathrm{~km})$, there is a strong outbreak of submesoscale currents in the upper ocean (Capet et al. 2008b). In the Peru region it takes the form of horizontal temperature fronts and filaments (McWilliams et al. 2009a) and spiral eddies. In this submesoscale regime, $\overline{w^{\prime} b^{\prime}}$ increases substantially compared to the mesoscale regime (Fig. 10). This indicates a more active boundary-layer restratification flux. However, this intensification does not greatly modify the vertically-integrated heat balance in our simulations because the increased restratifying eddy flux is largely compensated for by an increase in the destratifying flux of the boundary-layer turbulent mixing $\mathcal{D}$ through a modest increase in mean stratification within the boundary layer, although it raises interesting questions about small-scale upper ocean processes.

Thus, the depth-integrated heat balance is dominated by eddy advection $\mathcal{A}_{\text {eddy }}$ in combination with $Q_{a t m}$ heating and $\mathcal{A}_{\text {mean }}$ cooling, where the Ekman advection is usually a modest fraction of $Q_{a t m}$. This conclusion is consistent, in particular, with the moored time series at $85^{\circ} \mathrm{W}, 20^{\circ} \mathrm{S}$ in the VOCALS region (Colbo and Weller 2007).

Two recent papers also examine the Southeast Pacific upper-ocean heat balance with an eddy-permitting coupled global climate model (Toniazzo et al. 2010) and an eddy-resolving global oceanic model (Zheng et al. 2010). Both see indications of significant eddy heating near the South American coast, and at least some occurrences of offshore eddy cooling, although their point-wise sampling errors in heat advection are large $\left(n . b\right.$., the $20^{\circ} \mathrm{S}$ section in Fig 5 of Toniazzo et al. 2010 and the maps in Figs. 4-6 and 12 in Zheng et al. 2010), as are ours. Toniazzo et al. (2010) conclude that both eddy and geostrophic advection are important (in particular at the $\left(85^{\circ} \mathrm{W}, 20^{\circ} \mathrm{S}\right)$ mooring site), but it stops short of quantitative mean estimates and has only a partial resolution of the mesoscale eddy field. It does see significant modulation of the near-surface ocean heat balance by longlived transients encompassing inter-annual variability. Zheng et al. (2010) conclude that the eddy advection is unimportant in the Southeast Pacific, and it has a grid resolution similar to our own simulation. However, its mean heating $Q_{a t m}$ is weaker than in observations and in our simulation, so the framing dilemma of how the oceanic surface stays cool is less acute, and the analysis averaging areas are so large that they mix together the weak-eddy, mid-ocean regime and the strongeddy, coastal-transition regime (its Tables 1 and 5). 


\section{Mesoscale Eddies}

Because of the importance of eddies in the regional heat balance (Sec. 4), we further analyze their structure.

\subsection{SST Fronts}

Surface frontogenesis arises in a horizontal deformation flow (i.e., with a high strain rate) between the eddy centers (Capet et al. 2008b). A statistical measure of frontal activity is the probability density function (PDF) of $|\nabla S S T|$ (Castelao et al. 2006). PDFs are computed from our simulation and from satellite SST observations (OSTIA; Stark et al. 2007) in the Peru and Chile regions far enough offshore (> $300 \mathrm{~km}$ ) to exclude the main coastal upwelling fronts and filaments. Annual-mean PDFs approximately exhibit a power-law distribution in the tail $\left(P(x)=x^{-n}\right)$ indicative of strong, intermittent fronts. The exponent $n$ is smaller for Peru than Chile in both the model and measurements (e.g., the model has $n=$ is 0.18 and 0.23, respectively; Fig. 11), indicating stronger fronts in Peru. The observations show steeper PDF tails than the model (e.g., $n \simeq 0.7$ off Peru), probably due to the merging procedure applied in the satellite gridded data analysis (Reynolds and Chelton 2010) that yields a SST field much smoother than the nominal grid resolution (although we cannot rule out that our numerics overestimates to some extent SST gradients). Satellite observations and the present mesoscale simulation both underestimate the strong tail of SST gradient that occurs in simulations with submesoscale frontal dynamics (Capet et al. 2008b). Seasonal PDFs also have a power-law shape. The seasonal cycle is similar in both regions and in both the model and observations, with the greatest frontal activity in fall and the minimum in spring (see the $n$ values in the inset in Fig. 11). $n$ varies seasonally in phase with EKE.

\subsection{Vorticity}

The central extremum in a coherent eddy contributes to non-Gaussian tails in the PDF for vertical vorticity $\zeta^{z}$, and frontogenesis contributes to a positive (cyclonic) skewness at the surface (Hakim et al. 2002). Model PDFs for normalized vorticity $\zeta^{z} / f$ are in Fig. 12. At the surface they show positive skewness offshore of Peru and Chile, consistent with observations in many locations (Rudnick 2001). Besides the influence from frontogenesis, the negative tail can be limited by centrifugal instability to $\zeta^{z} / f>-1$, as suggested by the surface PDF for Peru. The PDFs also show intermittency in $\zeta^{z}$ with non-Gaussian tails. The normalized magnitudes are larger off Peru than Chile, partly because $f$ is smaller there. None of the vorticity values are much larger than $|f|$ in this mesoscale simulation, but much larger cyclonic values occur with submesoscale resolution. Large surface vorticity is a characteristic of sharpening of fronts and filaments by horizontal deformation flows, and presumably also of the eddies spawned by their instability (Capet et al. 2008b; Molemaker et al. 2010a; McWilliams et al. 2009a, 2009b). The vorticity amplitude is stronger at the surface than in the pycnocline. Interestingly, the skewness 
profiles become mostly negative in the pycnocline, indicating anticyclonic vorticity dominance (Fig. 12). The minimum skewness occurs at about $150 \mathrm{~m}$ depth off Peru and $250 \mathrm{~m}$ depth off Chile. Anticyclonic vorticity dominance is a characteristic of subsurface anticyclonic coherent vortices, which are widespread, long-lived eddies found many places around the world (often referred to as Submesoscale, Coherent Vortices, SCVs, even though some are mesoscale in size; McWilliams 1985). The depths of minimum skewness correspond to the depths of the PCUC in both regions (Sec. 3.2 and Fig. 4). In other eastern boundary regions, poleward undercurrents are known to shed subsurface anticyclonic vortices that propagate further westward to populate the oceanic interior, e.g., , Cuddies off California (Garfield et al. 1999), Meddies off the Iberian Peninsula (Armi and Zenk 1984), and Swoddies in the Bay of Biscay (Pingree and Le Cann 1992). The only report we know of such eddies in the PCS is Johnson and McTaggart (2010), who have shown subsurface anticyclones carrying equatorial water in a region offshore of Chile, with an inferred origin in the PCUC. The generation mechanism may be associated with intense instability in regions where the boundary current separates from the continental slope (D'Asaro 1988; Molemaker et al. 2010b).

\subsection{Coherent Eddies}

Next, we perform a census of the coherent vortex population using the eddy tracking method applied to the California Current System by Kurian et al. (2011). The method is based on closed-contour detections of the $Q$ parameter that combines vorticity and strain rate (Isern-Fontanet et al. 2003). We count an eddy as coherent if it passes the $Q$ shape criterion continuously for at least 30 days. The census spans ten years and is applied independently at different vertical levels for the Peru and Chile regions. Previous censuses for PCS surface eddies in altimeter observations are Chaigneau et al. (2008) and Chelton et al. (2007).

We first analyze the spatial structure of the coherent eddies and focus on detections at the PCUC level $(150 \mathrm{~m}$ in the Peru region, $250 \mathrm{~m}$ in the Chile region). We make a composite average over all vortices detected at the specified depth, both in vorticity (Fig. 13) and temperature anomaly relative to the local mean stratification (Fig. 14). Anomalies are defined with respect to a mean vertical profile, averaged within a box of $250 \times 250 \mathrm{~km}$ centered around the eddy, and computed for single instances of each eddy tracked (more details are given in Kurian et al. 2011).

The composite cyclone has its vorticity maximum at the surface, in spite of the detection test being made at the PCUC level. Chaigneau and Pizarro (2005) show observations in the region of a cyclonic eddy that is intensified at the surface but also has a signature over several hundred meters in depth, similar to the model result.

Subsurface-detected anticyclones have a different structure with the maximum vorticity located at depth. In the Peru region the vorticity core is around $100-150 \mathrm{~m}$ depth and is clearly isolated from the surface, resembling a mesoscale manifestation of a SCV. In Chile the composite-anticyclone core extends from the surface down to $250 \mathrm{~m}$ depth, without showing a distinct isolation from the surface. These vortex core depths roughly coincide with the negative skewness peaks in the $\zeta^{z} / f$ PDF (Fig. 12). Composite surface-detected anticyclones in the region (not shown) do not 
have such a deep extension for the vorticity core. The difference in the anticyclonic composite structure between the two regions may be due to the shallower and sharper thermocline off Peru that provides a more active barrier between the surface and the subsurface.

There is not clear asymmetry between detected cyclones and anticyclones numbers at depth in either region. But the mean vorticity of detected eddies, at the depths of the skewness peaks, is much larger in anticyclonic cores than in cyclonic cores (Fig. 13). So, anticyclones dominate the subsurface vorticity field.

The thermal structure of composite cyclones is a cold anomaly with a core magnitude of $1^{\circ} \mathrm{C}$ in both regions. The peak anomaly location is subsurface but still well above the detection depth. Subsurface anticyclones have different temperature anomaly patterns in the two regions. Off Peru there is a SCV-like lens structure in the isotherms that dome above the core and crater below it. In the Peru region both cyclonic and anticyclonic vortices have a cold temperature anomaly within the first $150 \mathrm{~m}$ depth. Off Chile the upper isotherm doming is not prominent, consistent with the vorticity connection between the PCUC and surface. The lower isotherms are depressed, so the vortex core has a warm anomaly.

In all cases in Fig. 14, the largest thermal anomaly is subsurface within the thermocline. This is consistent with the result in Sec. 4 that lateral eddy flux occurs mainly in the thermocline. Because we know both the eddy heat flux and the results of the vortex census, we can test the appealingly simple idea that the heat flux is a consequence of movement of coherent eddies that conserve their core thermal anomaly until the eddy eventually dies. Part of this simple idea is that the broader background area, outside of the coherent eddies, has an opposing lateral transport of water at the mean background temperature. To make this test we make the eddy detection in the upper thermocline where the lateral heat and buoyancy fluxes are maximal offshore, i.e., at $50 \mathrm{~m}$ depth off Peru and $150 \mathrm{~m}$ off Chile. Table 1 specifies how the coherent eddy flux estimate is made, and it compares the result to the total eddy flux, $u^{\prime} T^{\prime}$. Westward-propagating coherent cyclones are especially effective at offshore eastward heat flux because of their cold $T^{\prime}$ in the pycnocline (Fig. 14). Off Peru the coherent eddy contribution is about $20 \%$ of the total, and off Chile it is about $35 \%$. We do not view these estimates as precise, because eddy detection algorithms are not precise, but they do not change much with the detection-method parameters. Thus, the mechanism of coherent thermal anomaly transport is an appreciable fraction of the total flux (as suggested by Morrow et al. 2004), but flux contribution from "incoherent" eddy motions is even larger. An example of the latter is a cold temperature filament pulled offshore by a deformation flow between eddy centers (Fig. 1).

The subsurface core structure of the composite anticyclones (Fig. 13) supports the idea in Sec. 5.2 that these arise from instability of the PCUC and can be categorized as a type of SCV, characteristic of the PCS. This view is reinforced by looking at the composite-anticyclone salinity structure in the Chile region (Fig. 15). There is a well-defined central extremum of about 34.6 PSU around $250 \mathrm{~m}$ depth, which corresponds closely to the subsurface salinity maximum associated with the PCUC and is clearly distinct from the deep salinity minimum in the offshore region. The subsurface anticyclones in the Peru region do not have such a clear signature in salinity because the local PCUC itself is not as anomalous relative to the surrounding water. 
Table 1 Annual and areal mean of the eddy zonal temperature flux $u^{\prime} T^{\prime}\left[\mathrm{m} \mathrm{C} \mathrm{s}^{-1}\right]$ : total flux and fraction associated with the coherent eddies tracked for at least 30 days as detected by the method of Kurian et al. (2011). Fluxes are computed for the Peru region $\left(7-13^{\circ} \mathrm{S}\right)$ at $50 \mathrm{~m}$ depth with a cross-shore average between $50-650 \mathrm{~km}$ offshore and for the Chile region $\left(22-28^{\circ} \mathrm{S}\right)$ at $150 \mathrm{~m}$ depth between $50-350 \mathrm{~km}$ offshore. For the coherent eddies $u^{\prime} T^{\prime}$ is estimated as the average over all detected eddies of the triple product of $u^{\prime}$ taken as the zonal displacement speed of the eddy center, $T^{\prime}$ as the area-averaged temperature anomaly within the eddy core $\left(T^{\prime}=T-\bar{T}\right.$, with $\bar{T}$ the seasonal mean temperature at the location of the eddy), and the areal fraction within the eddy relative to the analysis domain.

\begin{tabular}{lcc}
\hline & Total $u^{\prime} T^{\prime}$ & Coherent eddy $u^{\prime} T$ \\
\hline Peru at $50 \mathrm{~m}$ depth & $12.5 \times 10^{-3}$ & $2.5 \times 10^{-3}$ \\
Chile at $150 \mathrm{~m}$ depth & $6.0 \times 10^{-3}$ & $2.1 \times 10^{-3}$ \\
\hline
\end{tabular}

\section{Intra-Seasonal Equatorial Boundary Forcing}

The Peru-Chile System is adjacent to the equator. Its coastline is an effective topographic waveguide for poleward propagation of equatorial perturbations. This is true at both inter-annual and intra-seasonal frequencies. ENSO is the dominant inter-annual component in nearshore currents off Peru (Huyer et al. 1987; Strub et al. 1998; Colas et al. 2008) and Chile (Blanco et al. 2002; Pizarro et al. 2002). Intra-seasonal variability of the nearshore currents with periods of 50-70 days arises through poleward propagation of coastally-trapped waves (Brink et al. 1983) that are unrelated to local wind variations, but more evidently related to intraseasonal equatorial variability (Kessler et al. 1995). Shaffer et al. (1997) show a pronounced variability of the PCUC off Chile. Intra-seasonal variability is stronger during ENSO periods. Another equatorial connection is between the subsurface Equatorial Countercurrents and the PCUC in the PCS (McCreary et al. 2002; Kessler 2006; Montes et al. 2010) ${ }^{5}$. The PCUC carries equatorial waters along the slope as far south as Chile and feeds the nearshore upwelled waters, as well as the subsurface coherent vortices generated by instability (Sec. 5).

By using mean-monthly open-boundary forcing (Sec. 2), this equatoriallygenerated variability is deliberately left out of our present simulation to focus on climate equilibrium. Now we test whether there is a climatological impact of the equatorial intra-seasonal variability by making another simulation with a setup identical to the primary one except for a modification of the open-boundary data: SODA is still used but the boundary data are updated every five days over the period 2000-2006. This allows both low- and high-frequency variability to enter the domain. To avoid extreme peaks of inter-annual variability, we choose a period without a strong ENSO event, so the dominant boundary variability is intra-seasonal. A comparison of the two simulations finds no significant difference in annual- and seasonal-mean stratification, SST structure, or nearshore currents, nor is there any important difference in the mean heat balance as analyzed in Sec. 4. However, the EKE does show an increase along the coast. At $50 \mathrm{~m}$ depth the increase is mainly in the Peru region ( $>50 \%$ increase locally), whereas at $150 \mathrm{~m}$ depth it is mainly in the Chilean region $(>30 \%)$; we interpret these as indications of equatorially-generated coastal waves. The offshore EKE shows no

5 This is different from the Equatorial Undercurrent, as sometimes suggested in previous studies that are based on coarse-resolution models (e.g., Cravatte et al. 2007). 
clear difference within, say, $20 \%$, comparable to the sampling estimation error. The only significant difference is an increase in EKE offshore of Peru north of $10^{\circ} \mathrm{S}$, which is broadly within the equatorial-coastal waveguide. Therefore, the important aspects of the mean heat balance in the PCS are robustly simulated with only monthly-mean forcing. Of course, there is important inter-annual variability during ENSO, but that is not our focus here.

\section{Sensitivity to Wind Forcing}

The coastal wind structure, within about $100-150 \mathrm{~km}$ of the shoreline, is of fundamental importance in the regional circulation and climate. For example, this structure controls the competition between Ekman transport and Ekman pumping in an upwelling system (i.e., nearshore stress magnitude and adjacent stress curl; Picket and Paduan 2003; Marchesiello et al. 2003; Capet et al. 2004). In this section we demonstrate the harmful consequences of a poor representation of the wind structure in global climate models, which may be a consequence of coarse horizontal resolution for the land-ocean transition and steep topography of the nearby Andes. Many atmospheric models have spectral basis functions and exhibit Gibbs noise in the PCS (Milliff and Morzel 2001; Large and Danabasoglu 2006). To illustrate the wind sensitivity we choose to use NCEP Reanalysis (Kalnay et al. 1996), viewing it as representative of global-model wind fields in lieu of systematic testing of other reanalyses or coupled-model solutions. We make another quasi-equilibrium simulation, SA-NCEP, similar to the one described in Sec. 2 but forced by NCEP monthly climatological wind stress (Fig. 17, right panels).

Coastal upwelling almost vanishes in the SA-NCEP solution, as shown by the weak isotherm tilt in Fig. 16. The annual-mean SST of the upwelled, nearshore water is approximately $20^{\circ} \mathrm{C}$ in SA-NCEP, substantially warmer than the $17^{\circ} \mathrm{C}$ in SA-QCOW. The reduction of upwelling is also evident in cross-shore sections of vertical velocity $w$ (Fig. 16). SA-QCOW has $w>0$ everywhere over the shelf and strongest near the coast, whereas SA-NCEP shows much weaker $w$ at the coast, and it is barely positive over the shelf. The reduced upwelling is due to a weaker alongshore wind in NCEP than in QSCAT particularly at the coast and within 200 $\mathrm{km}$ from the shore (Fig. 17). Lateral currents are also quite different in SA-NCEP (Fig. 16). The coastal equatorward surface current is weaker and more confined to the surface. The subsurface PCUC is reduced over the slope and occurs at a shallower depth. The biggest difference is that the SA-NCEP offshore poleward current dramatically increases, broadening over a few hundred $\mathrm{km}$ and reaching the surface between $100 \mathrm{~km}$ and $250 \mathrm{~km}$ offshore. The emergence of this strong poleward flow is related to the broad region of positive NCEP wind-stress curl by Sverdrup balance extending from 100 to $500 \mathrm{~km}$ offshore (Fig. 17); in contrast, the positive curl is confined within $150 \mathrm{~km}$ of the shore in QSCAT. The NCEP curl supports intense upward Ekman pumping, isotherm doming, and positive $w$ with maxima around $300 \mathrm{~km}$ offshore (Fig. 16). Within $100 \mathrm{~km}$ of the shore, the weaker NCEP curl causes reduced upward Ekman pumping.

Because the mean currents are different in SA-NCEP, the eddy field is too. Its EKE distribution in Fig. 17 is quite different from both the SA-QCOW and altimetry in Fig. 5. The EKE maxima are intensified and displaced offshore to west of $80^{\circ} \mathrm{W}$ off Peru and west of $75^{\circ} \mathrm{W}$ off Chile. The EKE maximum off Chile is 
confined north of $30^{\circ} \mathrm{S}$, whereas in observations it is around $33-34^{\circ} \mathrm{S}$, indicating a reduction of the mesoscale eddy activity south of $30^{\circ} \mathrm{S}$ in SA-NCEP. Adjacent to the coasts the eddies are too weak off Chile and too strong off Peru compared to altimetry. The heat balance in SA-NCEP still has cancellation between $Q_{a t m}$ and $\mathcal{A}$, as it must for the reasons explained in Sec. 4, but this occurs through very different relative contributions from $\mathcal{A}_{\text {mean }}$ and $\mathcal{A}_{\text {eddy }}$ (Fig. 18) compared to SA-QCOW. In association with the reduced upwelling in SA-NCEP, $\mathcal{A}_{\text {mean }}$ slackens within $150 \mathrm{~km}$ from the coast and does not provide enough cooling to balance $Q_{a t m}$. So, $\mathcal{A}_{\text {eddy }}$ is also cooling nearshore, in contrast to its strong warming in SA-QCOW. The total advection $\mathcal{A}$ accounts for less cooling (about $40 \mathrm{~W}$ $\mathrm{m}^{-2}$ ) in SA-NCEP within $200 \mathrm{~km}$ of the shore compared to SA-QCOW; this is a consequence of the nearshore warm SST bias in SA-NCEP, which causes a reduction in $Q_{a t m}$ through the correction from SST-restoring (Sec. 2). The advection patterns are also quite different offshore. $\mathcal{A}_{\text {mean }}$ is a strong cooling, related to the broad, upward Ekman pumping and mean isotherm doming. Consequently, $\mathcal{A}_{\text {eddy }}$ provides an offshore warming (vs. cooling in SA-QCOW) that acts to limit the isotherm doming.

Thus, SA-NCEP differs from SA-QCOW in many aspects like coastal upwelling dynamics, offshore circulation, eddy activity, and heat balance. Compared to SAQCOW, the SA-NCEP simulation exhibits an unambiguous degradation of its degree of agreement with observations; in particular it has a warm SST bias. This demonstrates the importance of an accurate wind field for the regional circulation, hence for the regional climate. Other global models (reanalysis or coupled) are, of course, different from NCEP, but we hypothesize they may have similar difficulties in accurately representing the climate of the PCS, as evident in their model biases (de Szoeke et al. 2010, Zheng et al. 2011).

\section{Conclusions}

The PCS has persistent regional biases in global climate models with potentially important upscaling effects to the basin and global scales. The central climate phenomenon is the stratus cloud deck that owes its existence to the relatively cold SST that is maintained by offshore oceanic cooling transport in the presence of net atmospheric heating. We have shown how this oceanic transport occurs in a regional quasi-equilibrium oceanic simulation that adequately resolves the upwelling circulation and mesoscale eddies. The mean offshore Ekman transport of upwelled cold water is too small to achieve this balance by about a factor of 2. Thus, a combination of both the total mean-flow advection and the eddy flux is necessary to sustain the offshore oceanic cooling. This offshore cooling occurs in the subsurface (upper thermocline) but episodic vertical mixing provides the connection with the surface.

The coastal upwelling circulation is the principal source of near-surface cold water that is then advected further offshore while generating mesoscale eddies. Cyclonic vortices tend to dominate the surface field, whereas anticyclonic vortices dominate the subsurface. The PCUC is of central importance because it carries water from the subsurface Equatorial Countercurrents along the coasts of Peru and Chile and disperses it through coherent anticyclones with salty cores. 
In global climate models coarse horizontal resolution is a source of regional biases because it leads to a misrepresentation of the oceanic upwelling circulation, PCUC, and mesoscale eddies. However, we also show that there would be no obvious benefit in increasing the oceanic model resolution while keeping an atmospheric model resolution with wind-structure biases. Higher resolution in the atmosphere is apparently a necessary step, and it can lead to improvements in the Southeast Pacific (Gent et al. 2009; Navarra et al. 2008; however, in these examples the warm SST and alongshore wind biases are only partially reduced). There is still a gap to cross in spatial resolution. This argues for regional coupled models that capture the nearshore mesoscale wind and currents (Boe et al. 2011) and for multi-scale models that allow for upscaling.

Acknowledgements Support was provided by the Office of Naval Research, grant N0001408-1-0597 and the National Science Foundation, grant ATM-0747533 (VOCALS program). The altimeter products were produced by SSALTO-DUACS and distributed by AVISO with support from CNES. The AVHRR-Pathfinder SST data were obtained from the Physical Oceanography Distributed Active Archive Center (PO.DAAC) at the NASA Jet Propulsion Laboratory. The CARS climatology is from the CSIRO Marine Laboratories. The sea surface temperature product OSTIA is from U.K. Meteorological Office data. Some of the computations were made at the National Center for Supercomputer Applications (NCSA). We thank Alexander Shchepetkin for his sustained effort to improve the ROMS model and thorough knowledge of parallel computing.

\section{References}

1. Armi, L. and W. Zenk, 1984: Large lenses of highly saline Mediterranean water. J Phys Oceanogr, 14:1560-1576.

2. Barnier, B., L. Siefried, and P. Marchesiello, 1995: Thermal forcing for a global ocean circulation model using a three-year climatology of ECMWF analyses. J Mar Sys, 6:363-380.

3. Becker, J.J., D.T. Sandwell, W. Smith, et al., 2009: Global Bathymetry and elevation data at 30 arc seconds resolution: SRTM30 PLUS. Marine Geodesy, 32:355-371.

4. Blanco, J.L., M.E. Carr, A.C. Thomas, and P.T. Strub, 2002: Hydrographic conditions off Northern Chile during the 1996-1998 La Niña and El Niño events. J Geophys Res, 107:3017. doi:10.1029/2001JC001002

5. Blanco, J.L., A.C. Thomas, M.-E. Carr, and P.T. Strub, 2001: Seasonal climatology of hydrographic conditions in the upwelling region off northern Chile. J Geophys Res, 106:1145111467.

6. Boe, J., A. Hall, F. Colas, J.C. McWilliams, X. Qu, and J. Kurian, 2011: What shapes mesoscale wind anomalies in coastal upwelling zones ? Clim Dyn, 36, 11-12, 2037-2049, doi:10.1007/s00382-011-1058-5.

7. Brink, K.H., D. Halpern, A. Huyer, and R.L. Smith, 1983: The physical environment of the Peruvian upwelling system. Prog Oceanography, 12:185-205.

8. Capet, X., F. Colas, P. Penven, P. Marchesiello, and J.C. McWilliams, 2008a : Eddies in eastern-boundary subtropical upwelling systems. Eddy-Resolving Ocean Modeling, AGU Monograph, vol.177, Washington DC, p.350.

9. Capet, X., P. Marchesiello, and J.C. McWilliams, 2004: Upwelling response to coastal wind profiles. Geophys Res Lett, 31:L13311. doi:10.1029/2004GL020123

10. Capet, X., J.C. McWilliams, M.J. Molemaker, and A.F. Shchepetkin, 2008b: Mesoscale to submesoscale transition in the California Current System. part I: Flow structure, eddy flux, and observational tests. J Phys Oceanogr, 38:29-43. doi:11756/2007JPO3671.1

11. Carton, J. and B. Giese, 2008: A reanalysis of ocean climate using Simple Ocean Data Assimilation (SODA). Mon Weather Rev, 136:2999-3017. doi:10.1175/2007MWR1978.1

12. Casey, K.S. and P. Cornillon, 1999: A comparison of satellite and in situ based sea surface temperature climatologies. J Clim, 12:1848-1863. 
13. Castelao, R.M. and J.A. Barth, 2006: The relative importance of wind strength and alongshelf bathymetric variations on the separation of a coastal upwelling jet. J Phys Oceanogr, 36:412-425. doi:10.1175/JPO2867.1

14. Castelao, R.M., T. Mavor, J.A. Barth, and L. Breaker, 2006: Sea surface temperature fronts in the California Current System from geostationary satellite observations. J Geophys Res, 111:C09026, doi:10.1029/2006JC003541.

15. Chaigneau, A., A. Gizolme, and C. Grados, 2008: Mesoscale eddies off Peru in altimeter records: identification algorithms and eddy spatio-temporal patterns. Prog Oceanography, 79:106-119. doi:10.1016/j.pocean.2008.10.013

16. Chaigneau, A. and O. Pizarro, 2005: Eddy characteristics in the eastern South Pacific. J Geophys Res, 110:C06005, doi:10.1029/2004JC002815.

17. Chelton, D.B., M.G. Schlax, R.M. Samelson, and R.A. de Szoeke, 2007: Global observations of large oceanic eddies. Geophys Res Lett, 34:L15606, doi:10.1029/2007GL030812.

18. Colas, F., X. Capet, J.C. McWilliams, and A.F. Shchepetkin, 2008: 1997-98 El Niño off Peru: A numerical study. Prog Oceanography, 79:138-155. doi:10.1016/j.pocean2008.10.1015 19. Colbo, K. and R.A. Weller, 2007: The variability and heat budget of the upper ocean under the Chile-Peru stratus. J Mar Res, 65:607-637. doi:1357/002224007783649510

20. Collins, W.D. et al., 2006: The Community Climate System Model version 3 CCSM. J Clim, 19:2122-2143. doi:10.1175/JCLI13761.1

21. Cravatte, S., G. Madec, T. Izumo, C. Menkes, and A. Bozec, 2007: Progress in the 3-d circulation of the eastern equatorial Pacific in a climate ocean model. Ocean Model, 17:28-48. doi:10.1016/j.ocemod.2006.11.003

22. Cronin, M.F., N.A. Bond, C.W. Fairall, and R.A. Weller, 2006: Surface cloud forcing in the east Pacific stratus deck/cold tongue/ITCZ complex. J Clim, 19:392-409. doi:10.1175/JCLI3620.1

23. Da Silva, A.M., CC.. Young, and S. Levitus, 1994: Atlas of surface marine data 1994, Vol. 1, Algorithms and procedures. NOAA Atlas NESDIS, 6, 74 pp.

24. D'Asaro, E., 1988: Generation of submesoscale vortices: A new mechanism. J Geophys Res, 93:6685-6693.

25. de Boyer-Montegut, C., G. Madec, A.S. Fischer, A. Lazar, and D. Iudicone, 2004: Mixed layer depth over the global ocean: An examination of profile data and a profile-based climatology. J Geophys Res, 109, doi:10.1029/2004JC002378.

26. de Szoeke, S.P., C.W. Fairall, D.E. Wolfe, L. Bariteau, and P. Zuidema, 2010: Surface flux observations on the southeastern tropical Pacific Ocean and attribution of SST errors in coupled ocean-atmosphere models. J Clim, 23:4152-4174. doi:10.1175/2010JCLI3411.1

27. Estrade, P., P. Marchesiello, A. Colin de Verdiere, and C. Roy, 2008: Cross-shelf structure of coastal upwelling: A two dimensional extension of Ekman theory and a mechanism for inner shelf upwelling shut down. J Mar Res, 66:589-616. doi:10.1357/002224008787536790

28. Flierl, G.R. and J.C. McWilliams, 1979: On the sampling requirements for measuring moments of eddy variability. J Mar Res, 35:797-820.

29. Garfield, N., C.A. Collins, R.G. Paquette, and E. Carter, 1999: Lagrangian exploration of the California Undercurrent, 1992-95. J Phys Oceanogr, 29:560-583.

30. Gent, P.R., S.G. Yeager, R.B. Neale, S. Levis, and D.A. Bailey, 2009: Improvements in a half degree atmosphere-land version of the CCSM. Clim Dyn, doi:10.1007/s00382-009-06148.

31. Hakim, G.J., C. Snyder, and D.J. Muraki, 2002: A new surface model for cycloneanticyclone asymmetry. J Atmos Sci, 59:2405-2420.

32. Huyer, A., M. Knoll, T. Paluszkiewicz, and R.L. Smith, 1991: The Peru Undercurrent: A study in variability. Deep-Sea Res, 38:5247-5271, suppl. 1.

33. Huyer, A., R.L. Smith, and T. Paluszkiewicz, 1987: Coastal upwelling off Peru during normal and El Niño times, 1981-1984. J Geophys Res, 92:14297-14307.

34. Isern-Fontanet, J., J.E. Garcia-Ladona, and J. Font, 2003: Identification of marine eddies from altimetric maps. J Atmos Ocean Technol, 20:772-778.

35. Johnson, G.C. and K.E. McTaggart, 2010: Equatorial Pacific $13^{\circ} \mathrm{C}$ water eddies in the Eastern Subtropical South Pacific Ocean. J Phys Oceanogr, 40:226-235. doi:10.1175/2009JPO4287.1

36. Kalnay, E. et al., 1996: The NCEP/NCAR 40-year reanalysis project. Bull Amer Meteor Soc, $77: 437-471$.

37. Karstensen, J., 2004: Formation of the South Pacific shallow salinity minimum: A southern ocean pathway to the tropical Pacific. J Phys Oceanogr, 34:2398-2412. doi:10.1175/JPO.2634.1 
38. Kessler, W.S., 2006: The circulation of the eastern tropical Pacific: A review. Prog Oceanography, 69:181-217. doi:10.1016/j.pocean.2006.03.009

39. Kessler, W.S., M.J. McPhaden, and K.M. Weickman, 1995: Forcing of intraseaonsal Kelvin waves in the equatorial Pacific. J Geophys Res, 100:C6:10613-10631.

40. Kurian, J., F. Colas, X. Capet, J.C. McWilliams, and D.B. Chelton, 2011: Eddy properties in the California Current System. J Geophys Res, in press. doi:10.1029/2010JC006895.

41. Large, W.G. and G. Danabasoglu, 2006: Attributions and impacts of upper-ocean biases in CCSM3. J Clim, 19:2325-2346. doi:10.1175/JCLI3740.1

42. Large, W.G., J.C. McWilliams, and S.C. Doney, 1994: Oceanic vertical mixing: A review and a model with a nonlocal boundary layer parameterization. Rev Geophysics, 32:363-403.

43. Large, W.G. and S. Yeager, 2009: The global climatology of an interannually varying air-sea flux data set. Clim Dyn, 33:341-364. doi:1005/s00382-008-0441-3

44. Letelier, J., O. Pizarro, and S. Nunez, 2009: Seasonal variability of coastal upwelling and the upwelling front off central Chile. J Geophys Res, 114, doi:10.1029/2008JC005171.

45. Manganello, J.V. and B. Huang, 2009: The influence of systematic errors in the Southeast Pacific on ENSO variability and prediction in a coupled GCM. Clim Dyn, 32, doi:10.1007/s00382-008-0407-5.

46. Marchesiello, P., L. Debreu, and X. Couvelard, 2009: Spurious diapycnal mixing in terrain-following coordinate models: the problem and a solution. Ocean Model, 26:156-169. doi:10.1016/j.ocemod.2008.09.004

47. Marchesiello, P. and P. Estrade, 2007: Eddy activity and mixing in upwelling systems: a comparative study of northwest Africa and California regions. Int J Earth Sci, 98:299-308. doi:10.1007/s00531-007-0235-6

48. Marchesiello, P., J.C. McWilliams, and A.F. Shchepetkin, 2003: Equilibrium structure and dynamics of the California Current System. J Phys Oceanogr, 33:753-783.

49. Mason, E., M.J. Molemaker, A.F. Shchepetkin, F. Colas, J.C. McWilliams, and P. Sangra, 2010: Procedures for offline grid nesting in regional ocean models. Ocean Model, 35:1-15. doi:10.1016/j.ocemod.2010.05.007

50. Mason, E., F. Colas, M.J. Molemaker, A.F. Shchepetkin, C. Troupin, J.C. McWilliams, and P. Sangra, 2011: Seasonal variability of the Canary current: A numerical study. J Geopys Res, 116, doi:10.1029/2010JC006665.

51. McCreary, J.P., P. Lu, and Z. Yu, 2002: Dynamics of the Pacific subsurface countercurrents. J Phys Oceanogr, 32:2379-2404.

52. McWilliams, J.C., 1985: Submesoscale, coherent vortices in the ocean. Rev Geophysics, 23:165-182.

53. McWilliams, J.C., F. Colas, and M.J. Molemaker, 2009a: Cold filamentary intensification and oceanic surface convergence lines. Geophys Res Lett, 36:L18602. doi:10.1029/2009GL039402

54. McWilliams, J.C., M.J. Molemaker, and E.I. Olafsdottir, 2009b: Linear fluctuation growth during frontogenesis. J Phys Oceanogr, 39:3111-3129. doi:10.1175/2009JPO4186.1

55. Mechoso, C.M. and R. Wood, 2010: An abbreviated history of VOCALS. CLIVAR Exchanges, 53, April 2010.

56. Milliff, R. and J. Morzel, 2001: The global distribution of the time-average wind stress curl from NSCAT. J Atmos Sci, 58, 109-131.

57. Molemaker, M.J., J.C. McWilliams, and X. Capet, 2010a: Balanced and unbalanced routes to dissipation in an equilibrated Eady flow. J Fluid Mech, 654:35-63. doi:1017/s0022112009993272

58. Molemaker, M.J., J.C. McWilliams, and W.K. Dewar, 2010b: Submesoscale generation of mesoscale anticyclones in the California Undercurrent. J Phys Oceanogr, submitted.

59. Montes, I., F. Colas, X. Capet, and W. Schneider, 2010: On the pathways of the equatorial subsurface currents in the Eastern equatorial Pacific and their contributions to the PeruChile Undercurrent. J Geophys Res, 115:C09003, doi:10.1029/2009JC005710.

60. Morrow, R., F. Birol, D. Griffin and J. Sudre, 2004: Divergent pathways of cyclonic and anti-cyclonic ocean eddies. Geophys Res Lett, 31:L24311, doi:10.1029/2004GL020974.

61. Navarra, A., et al., 2008: Atmospheric horizontal resolution affects tropical climate variability in coupled models. J Clim, 21:730-750.

62. Pascual, A., Y. Faugere, G. Larnicol, and P.Y. Le Traon, 2006: Improved description of the ocean mesoscale variability by combining four satellite altimeters. Geophys Res Lett, 33:L02611, doi:10.1029/2005GL024633.

63. Penven, P., V. Echevin, J. Pasapera, F. Colas, and J. Tam, 2005: Average circulation, seasonal cycle, and mesoscale dynamics of the Peru Current System: A modeling approach. J Geophys Res, 110, doi:10.1029/2005JC002945110. 
64. Penven, P., P. Marchesiello, L. Debreu, and J. Lefevre, 2008: Software tools for preand post-processing of oceanic regional simulations. Environmental Modelling and Software, 23:660-662. doi:1016/j.envsoft.2007.07.004

65. Philander, S.G. and J.H. Yoon, 1982: Eastern boundary currents and coastal upwelling. J Phys Oceanogr, 12:862-879.

66. Pickett, M.H. and J.D. Paduan, 2003: Ekman transport and pumping in the California Current based on the U.S. Navy's high-resolution atmospheric model COAMPS. J Geophys Res, 108, doi:10.1029/2003JC001902.

67. Pingree, R.D. and B. Le Cann, 1992: Three anticyclonic Slope Water Oceanic eDDIES (SWODDIES) in the Southern Bay of Biscay. Deep-Sea Res, 39:1147-1175.

68. Pizarro, O., G. Shaffer, B. Dewitte, and M. Ramos, 2002: Dynamics of seasonal and interannual variability of the Peru-Chile Undercurrent. Geophys Res Lett, 29, doi:10.1029/2002GL014790.

69. Reynolds, R. and D.B. Chelton, 2010: Comparisons of daily Sea Surface Temperature analyses for 2007-08. J Clim, 23, 3545-3562, doi: 10.1175/2010JCLI3294.1.

70. Risien, C.M. and D.B. Chelton, 2008: A global climatology of surface wind and wind stress fields from eight years of QuikSCAT scatterometer data. J Phys Oceanogr, 38:2379-2413. doi:10.1175/2008.JPO.3881.1

71. Rudnick, D.L., 2001: On the skewness of vorticity in the upper ocean. Geophys Res Lett, 28:2045-2048.

72. Shaffer, G., S. Hormazabal, O. Pizarro, and S. Salinas, 1999: Seasonal and interannual variability of currents and temperature off central Chile. J Geophys Res, 104:29951-29961. 73. Shaffer, G., O. Pizarro, L. Djurfeldt, S. Salinas, and J. Ruttlant, 1997: Circulation and low-frequency variability near the Chilean coast : remotely forced fluctuations during the 1991-1992 El Niño. J Phys Oceanogr, 27:217-235.

74. Shchepetkin, A.F. and J.C. McWilliams, 2005: The Regional Oceanic Modeling System: A split-explicit, free-surface, topography-following-coordinate ocean model. Ocean Model, 9:347-404. doi:10.1016/j.ocemod.2004.08.002

75. Shchepetkin, A.F. and J.C. McWilliams, 2009: Correction and commentary for "Ocean forecasting in terrain-following coordinates: Formulation and skill assesment of the regional ocean modeling system" by Haidvogel et al., J. Comp. Phys. 227, pp.3595-3624. J Comp Phys, 228,24:8985-9000, doi:10.1016/j.jcp.2009.09.002.

76. Stark, J.D., C.J. Donlon, M.J. Martin, and M.E. McCulloch, 2007: An operational, high resolution, real time, global sea surface temperature analysis system. Marine Challenges: Coastline to Deep Sea. Aberdeen, Scotland. IEEE.

77. Strub, P.T., J.M. Mesias, V. Montecino, J. Ruttlant, and S. Salinas, 1998: The Sea, Vol. 11, chap. 10: Coastal ocean circulation off western South America, 29-67. John Wiley \& Sons. 78. Toniazzo, T., R.C. Mechoso, L.C. Shaffrey, and J.M. Slingo, 2010: Upper-ocean heat budget and ocean eddy transport in the southeast Pacific in a high-resolution coupled model. Clim Dyn, 35: 1309-1329, doi:10.101007/s00382-009-0703-8.

79. Veitch, J., P. Penven, and F. Shillington, 2010: Modelling equilibrium dynamics of the Benguela Current System. J Phys Oceanogr, 40:1942-1964. doi:10.1175/2010JPO4382.1

80. Wood, R., C.R. Mechoso, C. Bretherton, B. Huebert, and R. Weller, 2007: The VAMOS Ocean-Cloud-Atmosphere-Land Study (VOCALS). CLIVAR Variations Newsletter, 5, 1:1-5. 81. Xie, S., et al., 2007: A regional ocean-atmosphere model for Eastern Pacific climate: Toward reducing tropical biases. J Clim, 20, 1:1504-1522. doi:10.1175/JCLI4080.1

82. Yu, J.Y. and C.R. Mechoso, 1999: Links between annual variations of Peruvian stratocumulus clouds and of SST in the Eastern Equatorial Pacific. J Clim, 12:3305-3318.

83. Yu, L. and R.A. Weller, 2007: Objectively analyzed air-sea heat fluxes for the global ice-free oceans (1981-2005). Bull Amer Meteor Soc, 88:527-539. doi:10.1175/bams-88-4-527

84. Zheng, J., T. Shinoda, G.N. Kiladis, J. Lin, E.J. Metzger, H.E. Hurlburt, and B.S. Giese, 2010: Upper-ocean processes under the stratus cloud deck in the Southeast Pacific Ocean. J Phys Oceanogr, 40:103-120. doi:10.1175/2009JPO4213.1

85. Zheng, J., T. Shinoda, J.L. Lin, and G.N. Kiladis, 2011: Sea surface temperature biases under the stratus cloud deck in the Southeast Pacific ocean in 19 IPCC AR4 coupled general circulation models. J Clim, in press. doi:10.1175/2011JCLI4172.1 

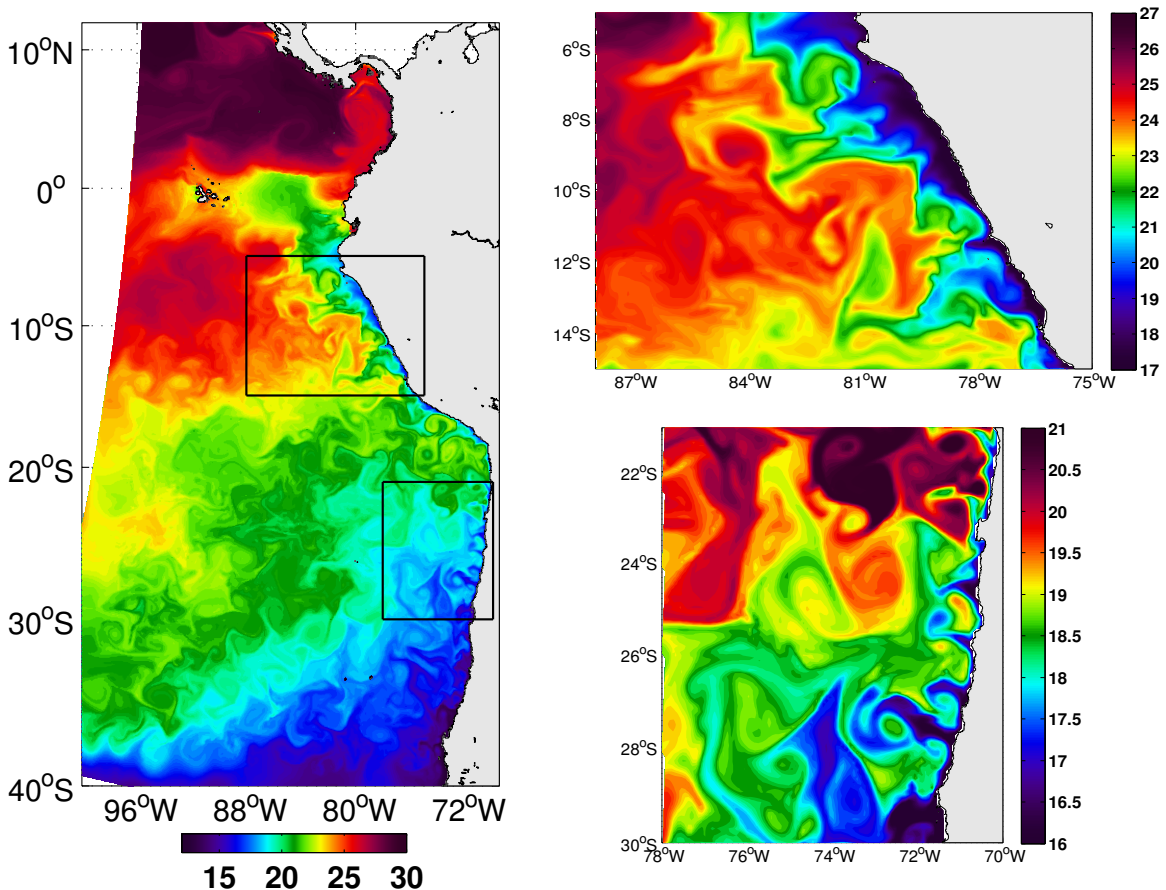

Fig. 1 Snapshot of simulated surface temperature $\left[{ }^{\circ} \mathrm{C}\right]$ in the fall over the entire model domain (left), with zooms (right) into the subdomains indicated by black boxes in the left panel. Northern and southern subdomains correspond, respectively, to the Peru and Chile regions, that are further analyzed in the study. Color scales are different for the three plots. 


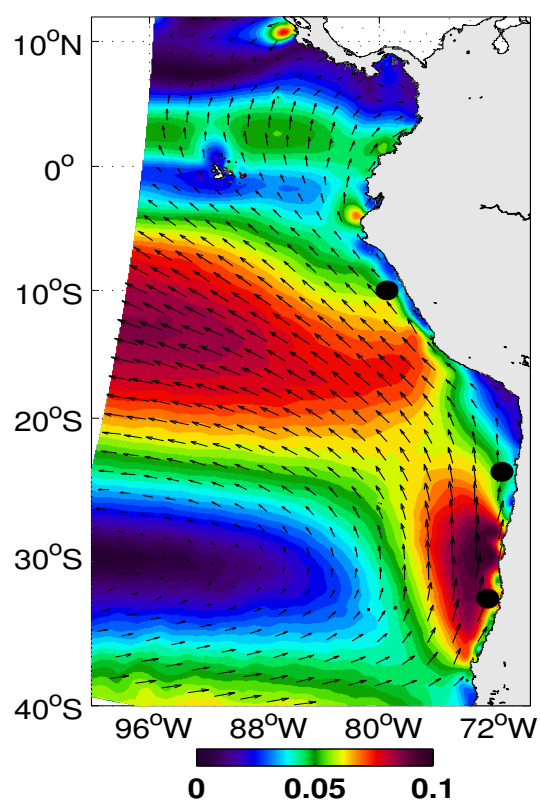

(a)

(b)
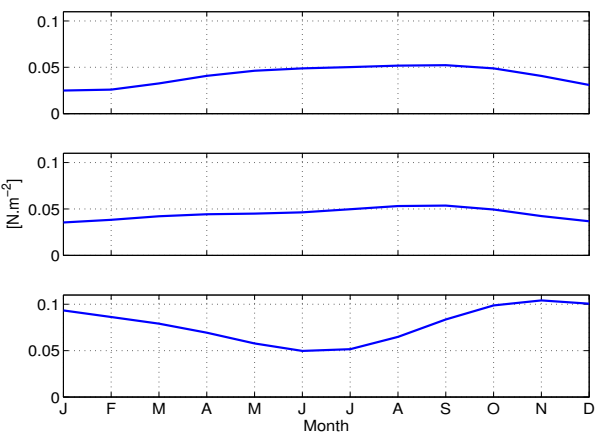

Fig. 2 (a) Annual mean of QSCAT (SCOW) wind stress magnitude $\left[\mathrm{N} \mathrm{m}^{-2}\right]$ and direction (arrows). (b) Annual cycle of the alongshore component $\tau^{y}$ at three different locations indicated by large black dots near the coast on the left panel. Subplots from top to bottom correspond to locations from north to south on the map.
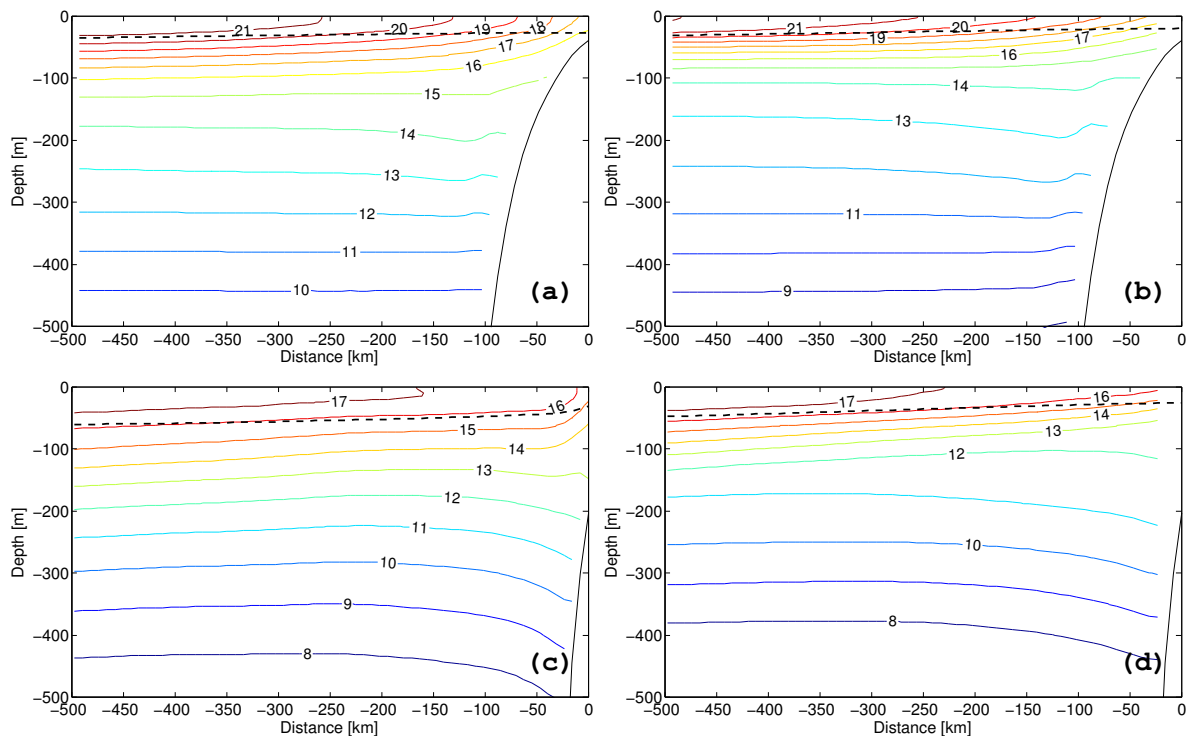

Fig. 3 Mean vertical sections of temperature, averaged between $7-13^{\circ} \mathrm{S}(\mathrm{a}, \mathrm{b})$ and between $22-$ $28^{\circ} \mathrm{S}$ (c, d), for the SA-QCOW simulation (left column) and CARS climatology (right column). Black dashed lines are the mixed-layer depth taken from the Boyer-Montegut climatology (right column) and computed for the model solution (left column; following the same $0.2^{\circ} \mathrm{C}$-criterion than Boyer-Montegut et al. 2004, see Sec.3.1). 

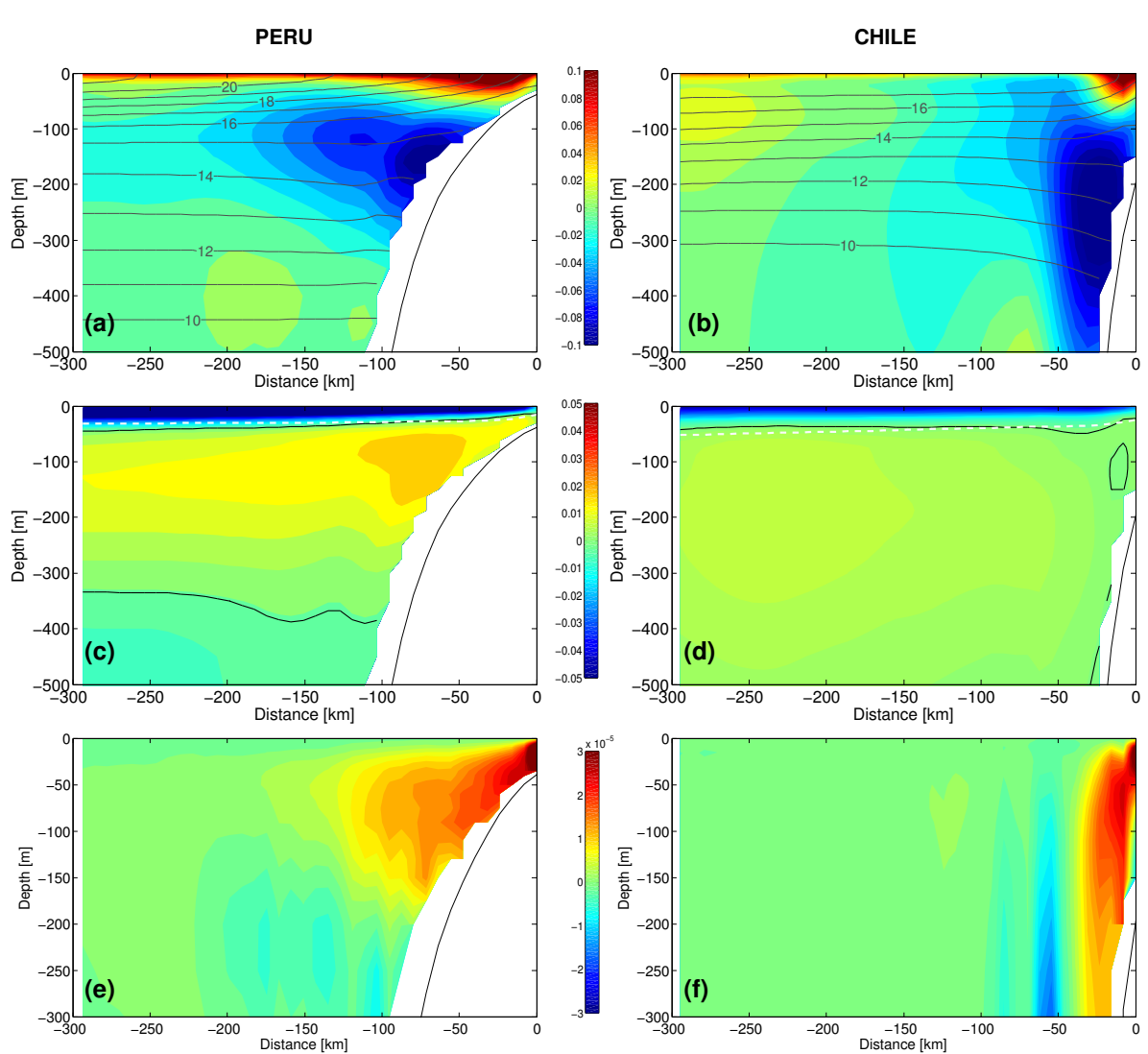

Fig. 4 (a,b) Vertical sections of mean alongshore velocity $\bar{v}\left[\mathrm{~m} \mathrm{~s}^{-1}\right]$ from the SA-QCOW simulation for the Peru and Chile regions, averaged between $7-13^{\circ} \mathrm{S}$ (left) and between $22-$ $28^{\circ} \mathrm{S}$ (right). Black contours represent the mean temperature with contour interval $1^{\circ} \mathrm{C} .(\mathrm{c}, \mathrm{d})$

Vertical sections of the mean cross-shore velocity $\bar{u}\left[\mathrm{~m} \mathrm{~s}^{-1}\right]$. Black contours are $\bar{u}=0$, and white dashed lines are the mixed-layer depth diagnosed by KPP. (e,f) Vertical sections of the mean vertical velocity $\bar{w}\left[\mathrm{~m} \mathrm{~s}^{-1}\right]$. 

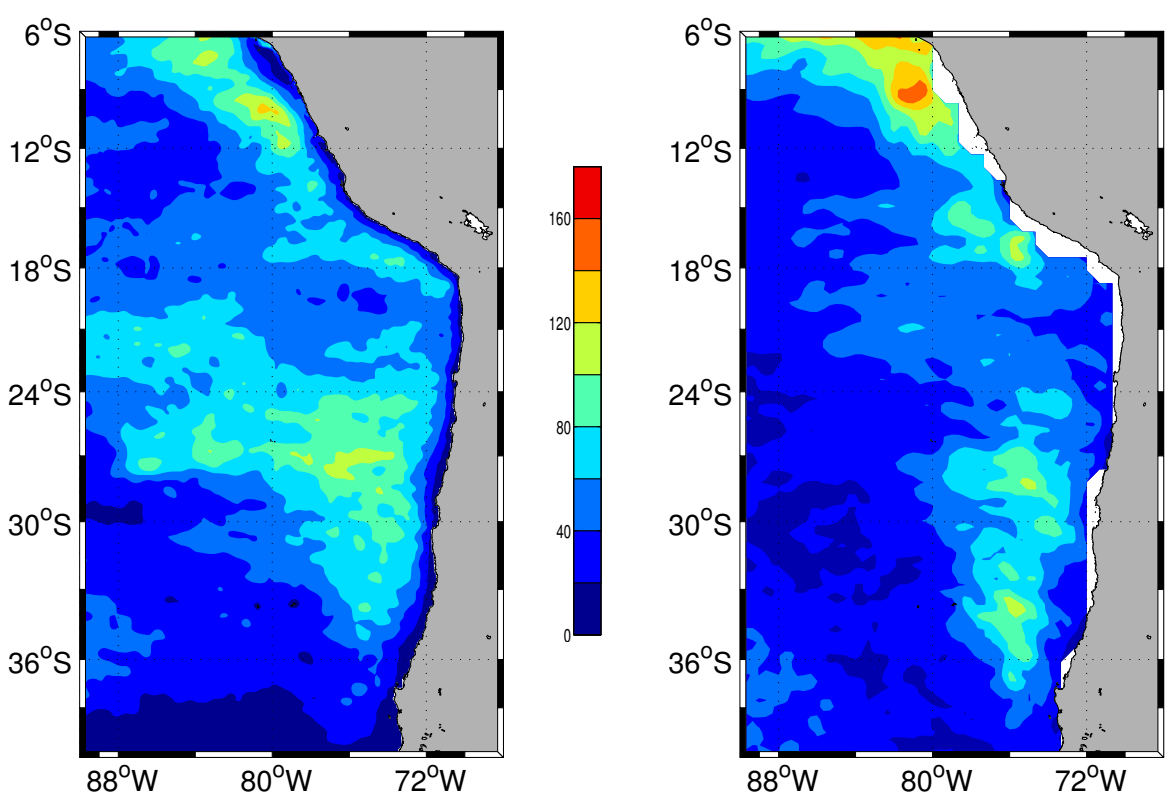

Fig. 5 Mean surface geostrophic eddy kinetic energy EKE $\left[\mathrm{cm}^{2} \mathrm{~s}^{-2}\right]$ for the SA-QCOW simulation (left) and AVISO (DUACS) altimetry (right).

PERU
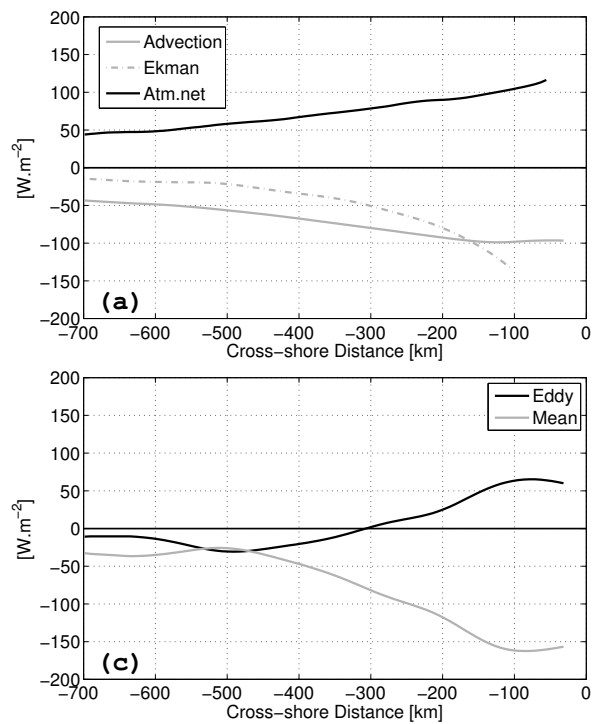

CHILE
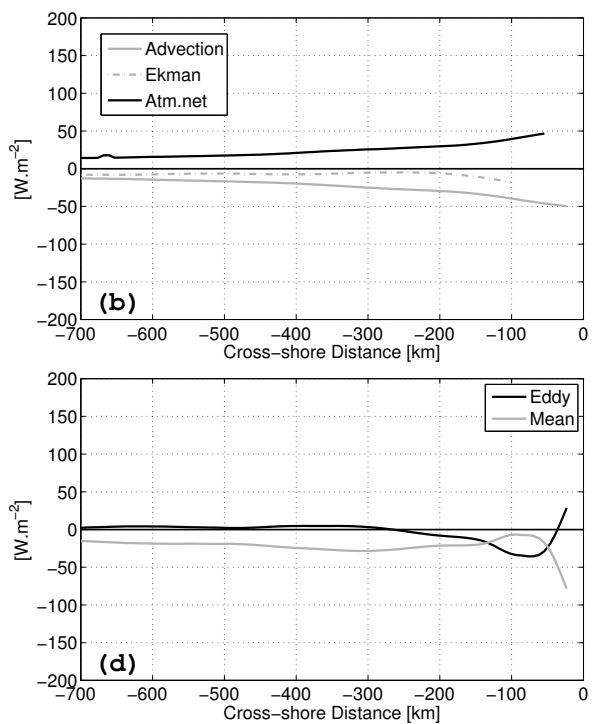

Fig. 6 Top row (a, b): total heat flux divergence, Ekman-transport contribution, and net airsea flux. Bottom row (c, d): annual-mean, vertically-integrated (0 to $200 \mathrm{~m}$ ) eddy and mean heat divergence $\left[\mathrm{W} \mathrm{m}^{-2}\right]$, averaged alongshore for two regions, $7-13^{\circ} \mathrm{S}$ (Peru on the left) and $25-35^{\circ} \mathrm{S}$ (Chile on the right). 


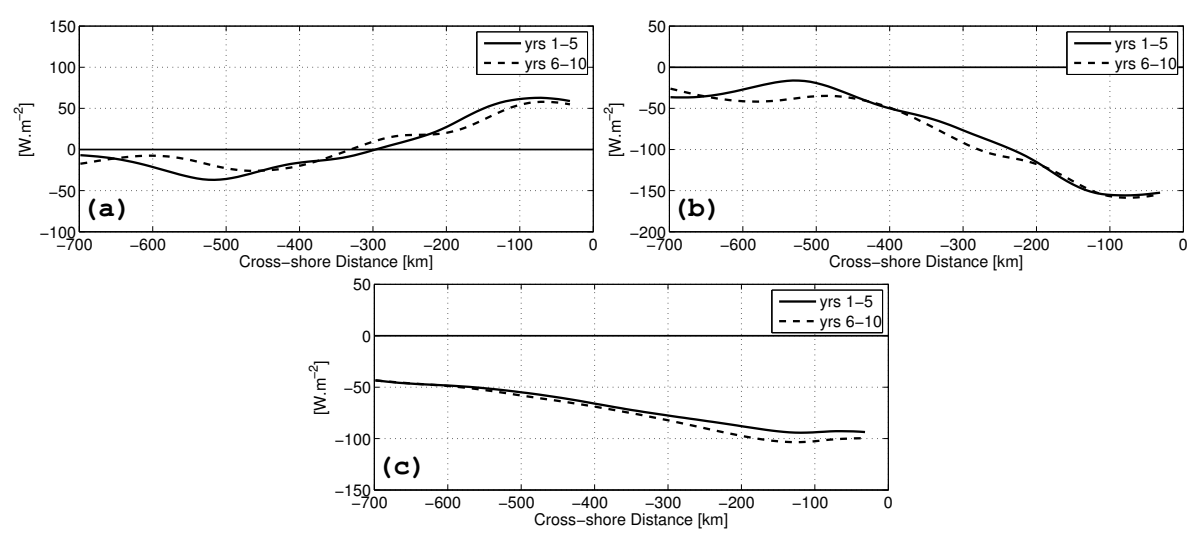

Fig. 7 Annual-mean, vertically-integrated $(0$ to $200 \mathrm{~m})$ heat flux divergence $\left[\mathrm{W} \mathrm{m}^{-2}\right]$, averaged alongshore between $7^{\circ} \mathrm{S}$ and $13^{\circ} \mathrm{S}$, for years 1 to 5 (solid lines) and years 6 to 10 (dashed lines): eddy (a), mean (b), and total (c).
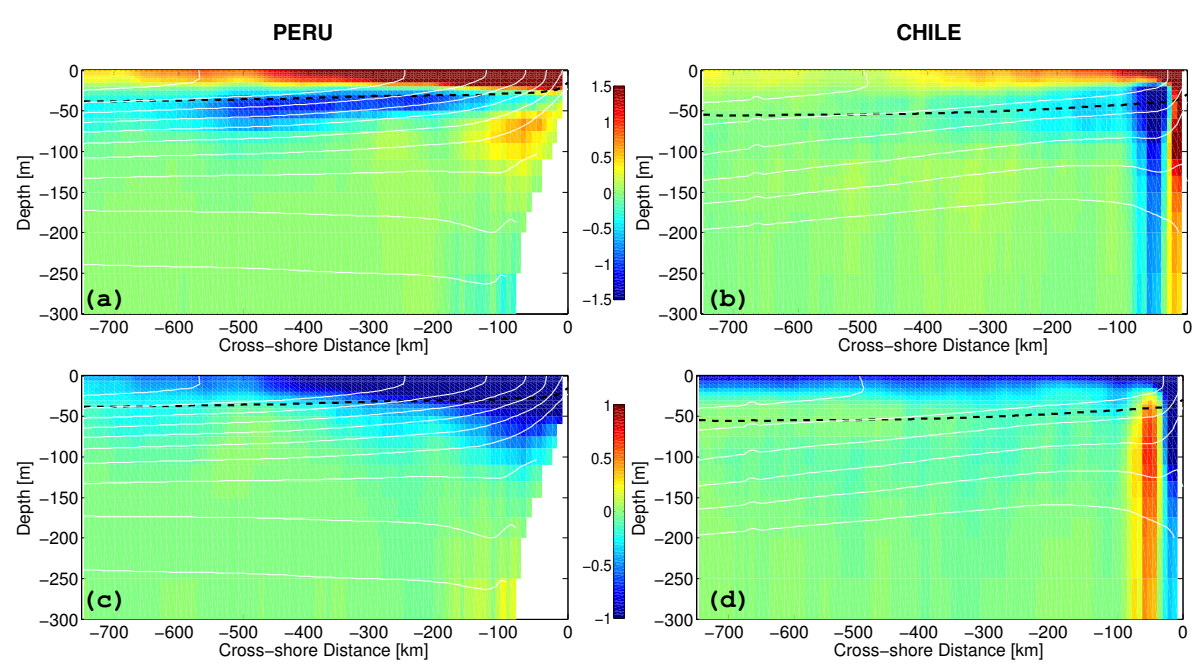

Fig. 8 Vertical sections of annual-mean heat flux divergence $\left[\mathrm{W} \mathrm{m}^{-3}\right]$, alongshore-averaged between $7-13^{\circ} \mathrm{S}$ (left panels) and $25-35^{\circ} \mathrm{S}$ (right panels): eddy (a,b) and mean (c,d). White contours are mean temperature $\left(1^{\circ} \mathrm{C}\right.$ interval), and the black dashed line is mixed-layer depth diagnosed by KPP. 

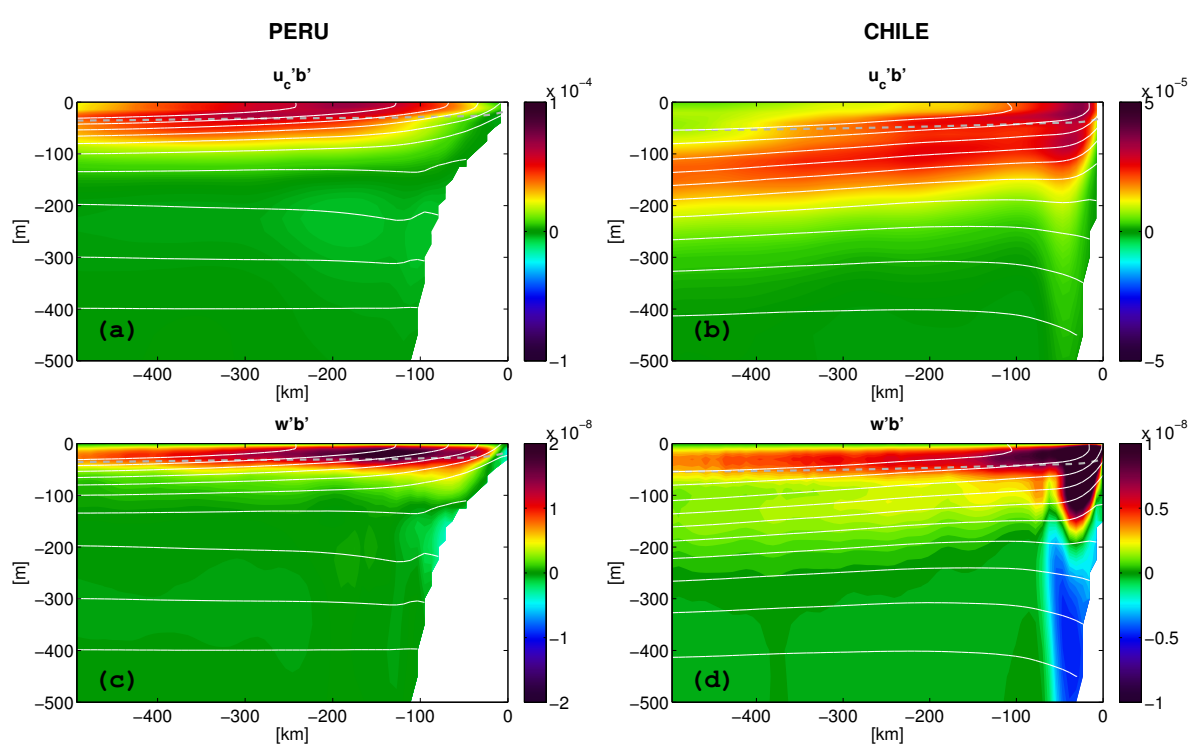

Fig. 9 Vertical sections of annual-mean of eddy buoyancy fluxes $\left[\mathrm{m}^{2} \mathrm{~s}^{-3}\right], u^{\prime} b^{\prime}(\mathrm{a}, \mathrm{b})$ and $w^{\prime} b^{\prime}(\mathrm{c}, \mathrm{d})$, averaged between $7-13^{\circ} \mathrm{S}$ (left panels) and between $25-35^{\circ} \mathrm{S}$ (right panels). White contours are the mean buoyancy field, and the gray dashed line is mixed layer depth diagnosed by KPP. Color scales are different for the Peru and Chile regions.

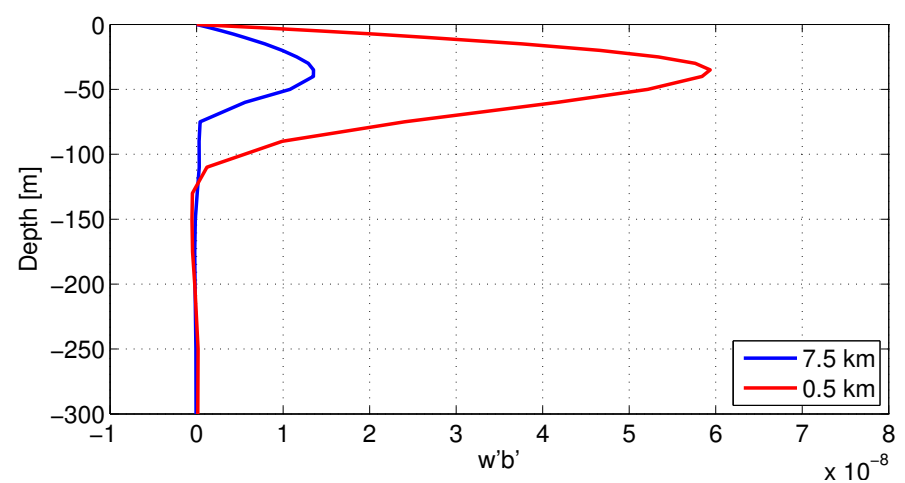

Fig. 10 Vertical profile of July-mean vertical eddy buoyancy flux $w^{\bar{\gamma}} b^{\prime}\left[\mathrm{m}^{2} \mathrm{~s}^{-3}\right]$ averaged over a region offshore of Peru from the SA-QCOW simulation (blue; resolution $\delta x=7.5 \mathrm{~km}$ ) and from a submesoscale solution (red; resolution $\delta x=0.5 \mathrm{~km}$; McWilliams et al., 2009a). The winter season is when $w^{\top} b^{\prime}$ is largest. 

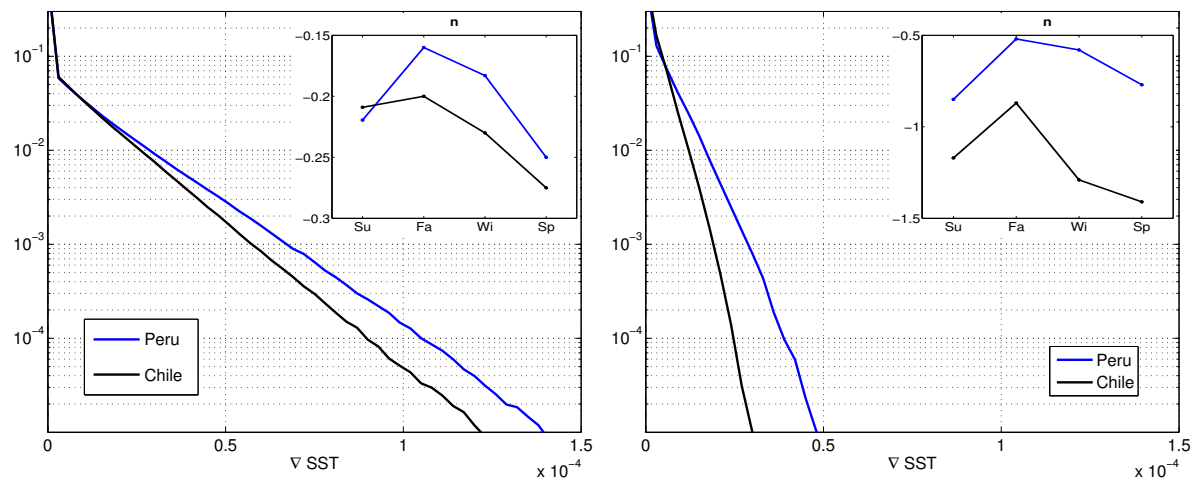

Fig. 11 All-season PDFs of sea-surface temperature gradient $\left[{ }^{\circ} \mathrm{C} \mathrm{m}^{-1}\right]$ for the SA-QCOW simulation (left) and for the OSTIA satellite observations (right) in two offshore regions off Peru (blue) and Chile (black). Inset plots are seasonal values of PDF power-law tail exponent $n$.

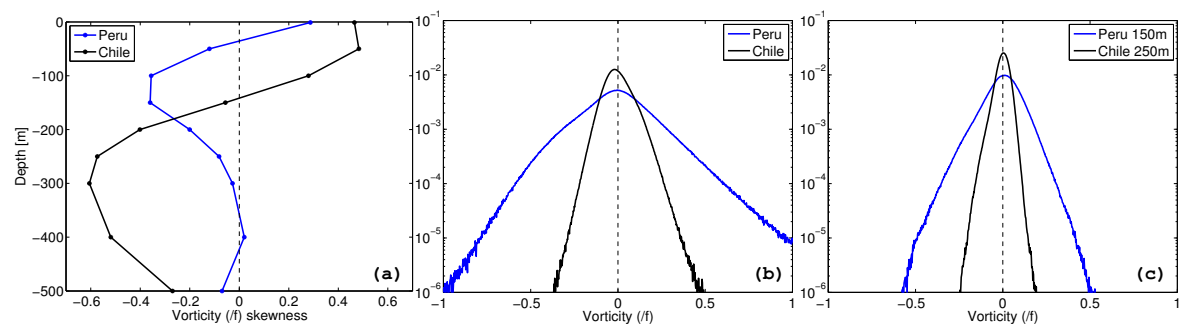

Fig. 12 Normalized vertical vorticity $\left(\zeta^{z} / f\right)$ offshore of Peru and Chile (i.e., 200-700 km from the coast): vertical profile of skewness (left) and PDF at the surface (center) and subsurface (right; at $150 \mathrm{~m}$ depth off Peru and $250 \mathrm{~m}$ depth off Chile). 

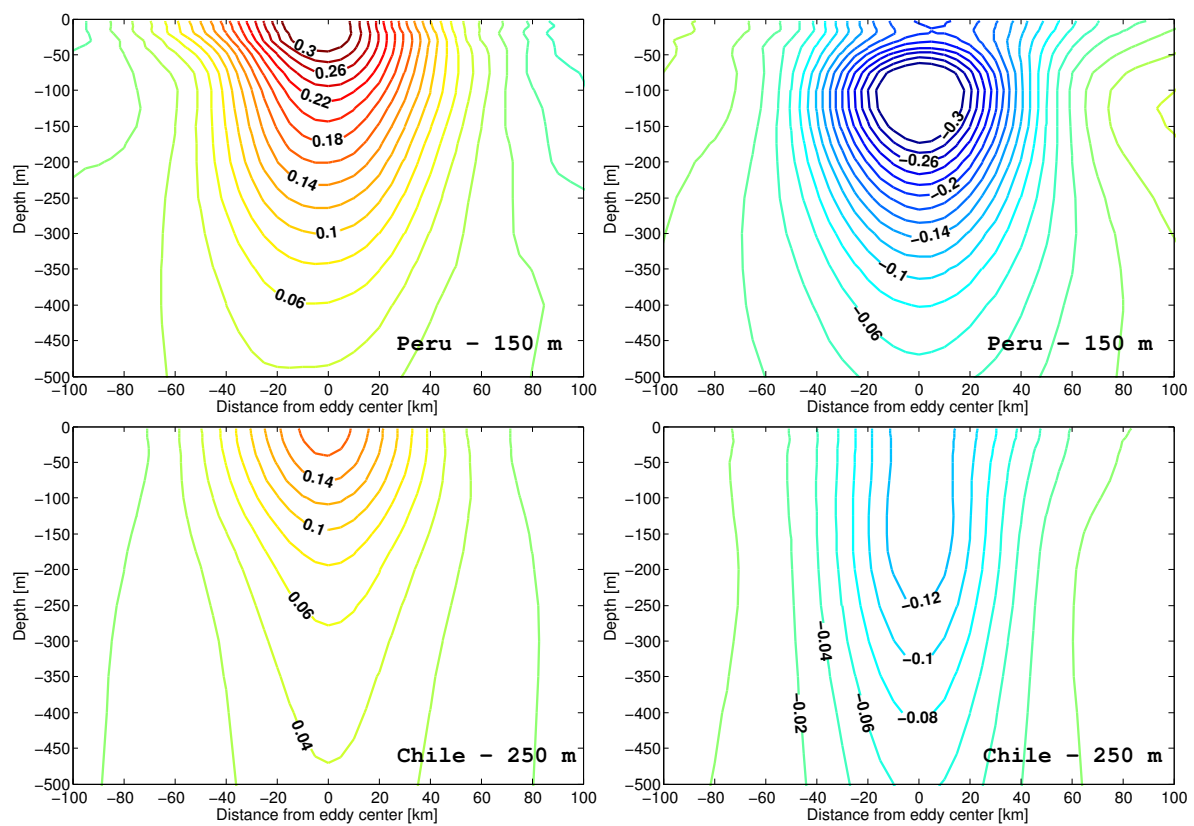

Fig. 13 Composite $\zeta^{z} / f$ structure of detected cyclones (left) and anticyclones (right), at 150 $\mathrm{m}$ depth off Peru (top row) and $250 \mathrm{~m}$ depth off Chile (bottom row).
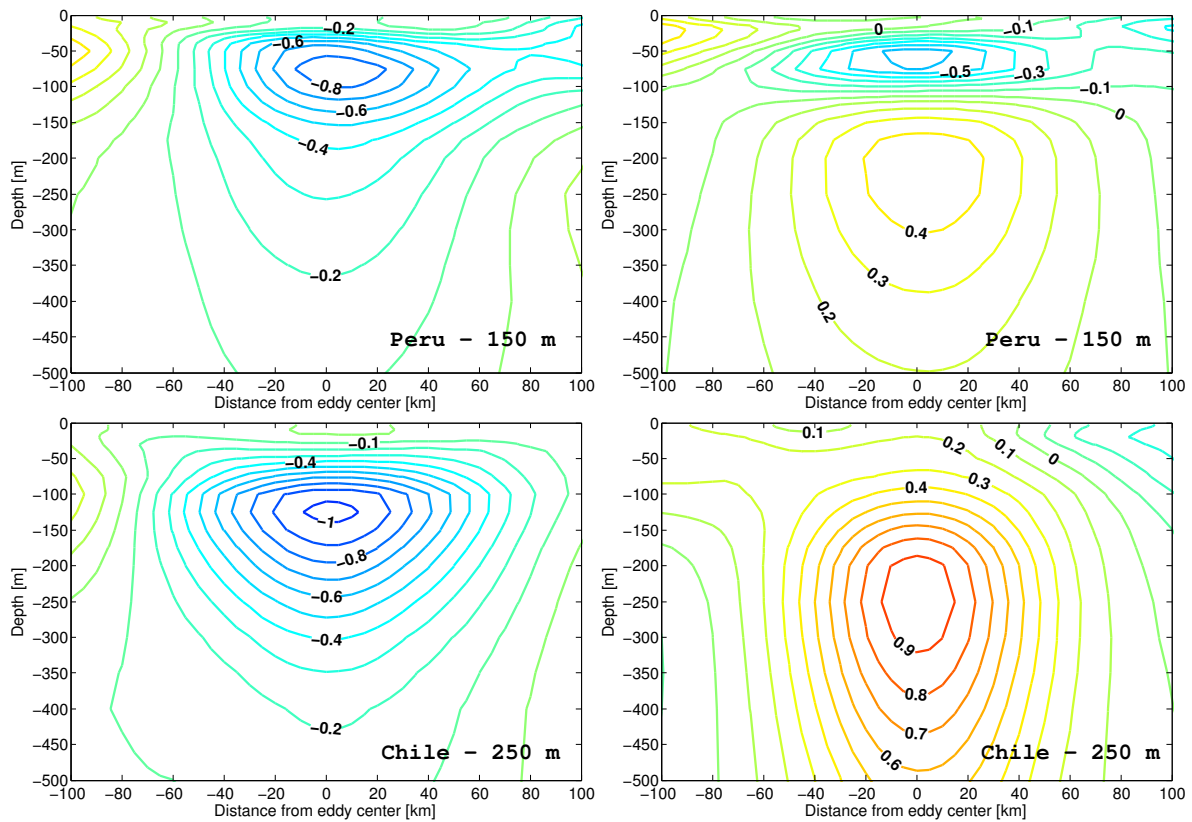

Fig. 14 Composite temperature anomaly structure of detected cyclones (left) and anticyclones (right) at $150 \mathrm{~m}$ depth off Peru (top) and $250 \mathrm{~m}$ depth off Chile (bottom). The anomaly is relative to the vertical profile averaged in a $200 \mathrm{~km} \times 200 \mathrm{~km}$ region around the eddy center. 

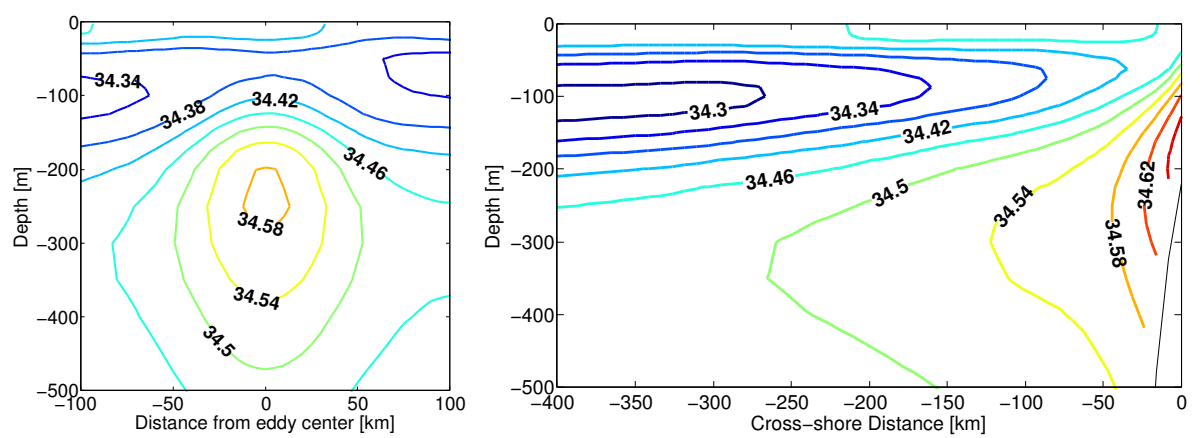

Fig. 15 (Left) Composite salinity structure of anticyclones detected at $250 \mathrm{~m}$ depth for Chile. (Right) Vertical section of mean salinity [PSU] averaged between $26-30^{\circ} \mathrm{S}$.
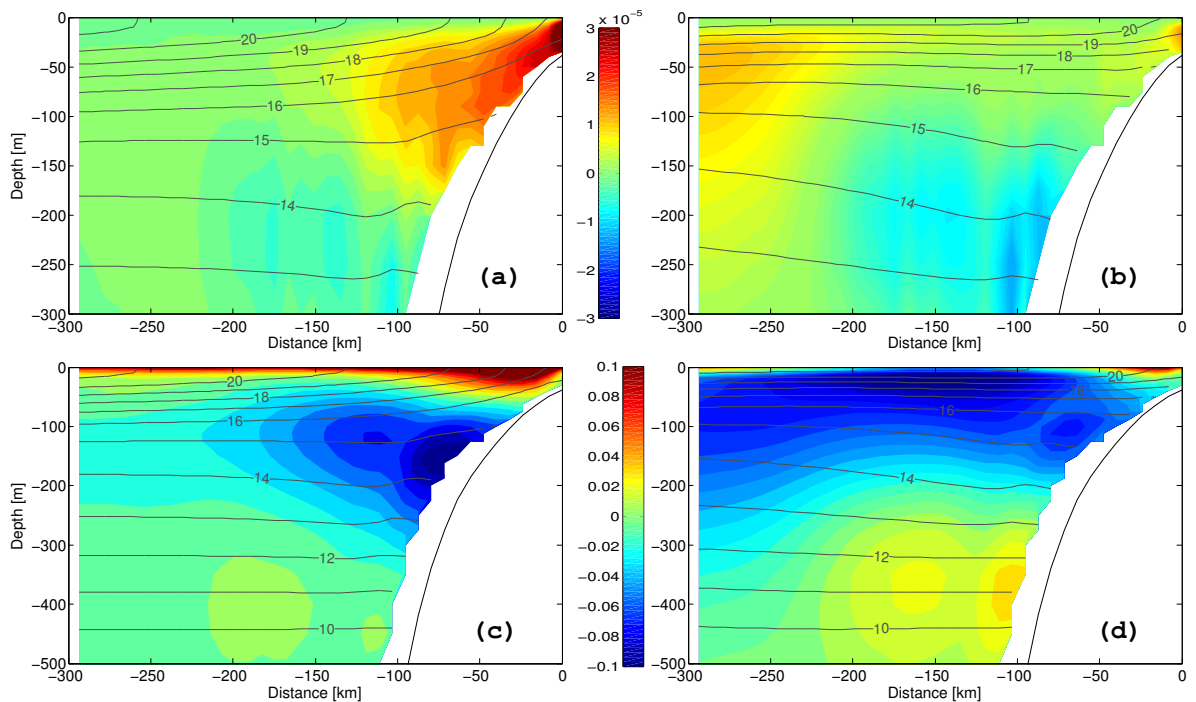

Fig. 16 Annual-mean, alongshore-averaged vertical section of the vertical velocity $\bar{w}(\mathrm{a}, \mathrm{b})$ and alongshore velocity $\bar{v}\left[\mathrm{~m} \mathrm{~s}^{-1}\right]$ (c, d) for Peru (7-13 $\left.\mathrm{S}\right)$. The left column is for the SAQCOW simulation ( $a, c)$, and the right column is for SA-NCEP (b, d). Black contours are the mean temperature $\left[{ }^{\circ} \mathrm{C}\right]$. Depth scales are different for $(\mathrm{a}, \mathrm{b})$ and $(\mathrm{c}, \mathrm{d})$. 

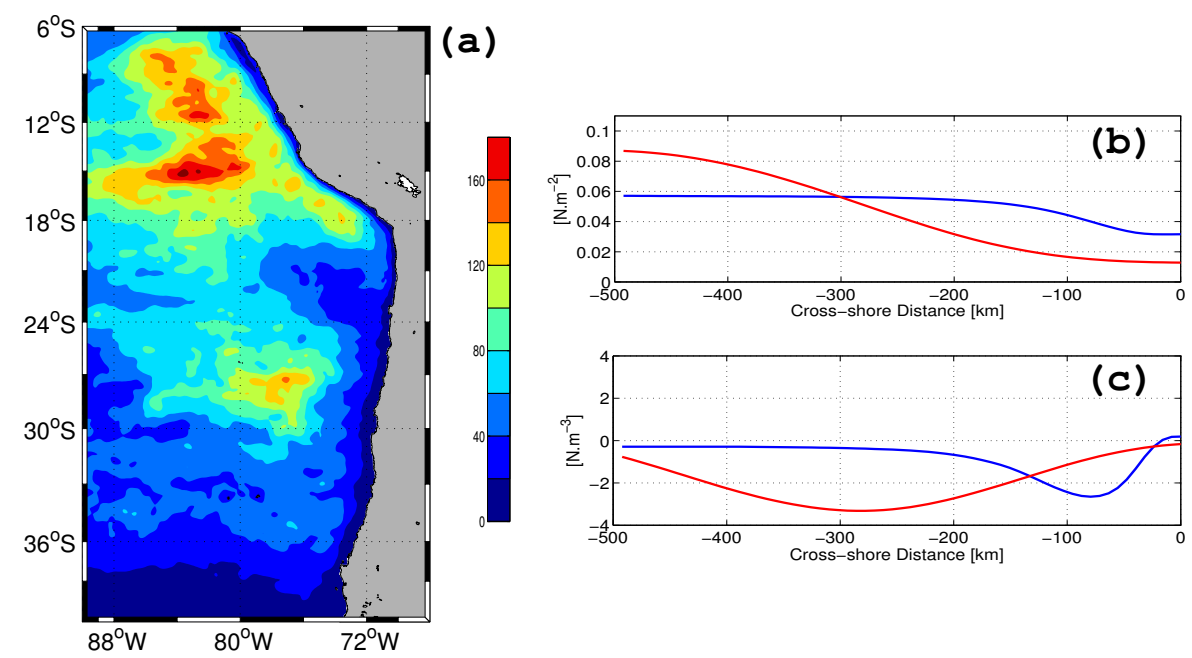

Fig. 17 (a) Eddy kinetic energy $\left[\mathrm{cm}^{2} \mathrm{~s}^{-2}\right]$ for SA-NCEP. Annual-mean, alongshore-averaged $\left(7-13^{\circ} \mathrm{S}\right)$ wind stress $\left[\mathrm{N} \mathrm{m}^{-2}\right]$ (b) and curl $\left[\mathrm{N} \mathrm{m}^{-3}\right]$ (c) for SA-QCOW (blue) and SA-NCEP (red).

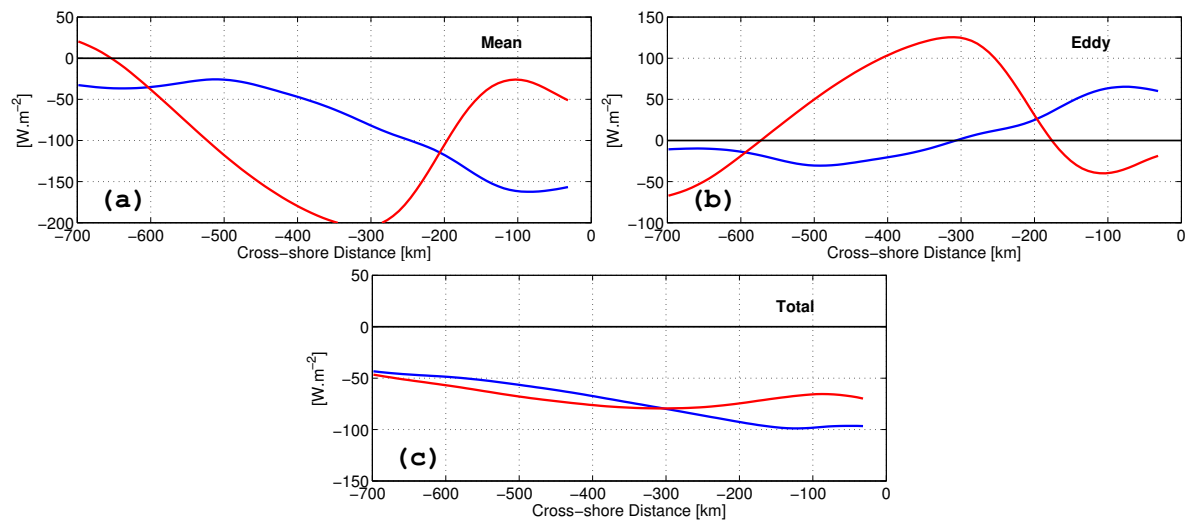

Fig. 18 Annual-mean, vertically-integrated $(0-200 \mathrm{~m})$, alongshore-averaged $\left(7-13^{\circ} \mathrm{S}\right)$ heat flux divergences for SA-QCOW (blue lines) and SA-NCEP (red lines): mean (a), eddy (b), and total (c). The mean air-sea flux $Q_{a t m}$ is minus the total advection. 